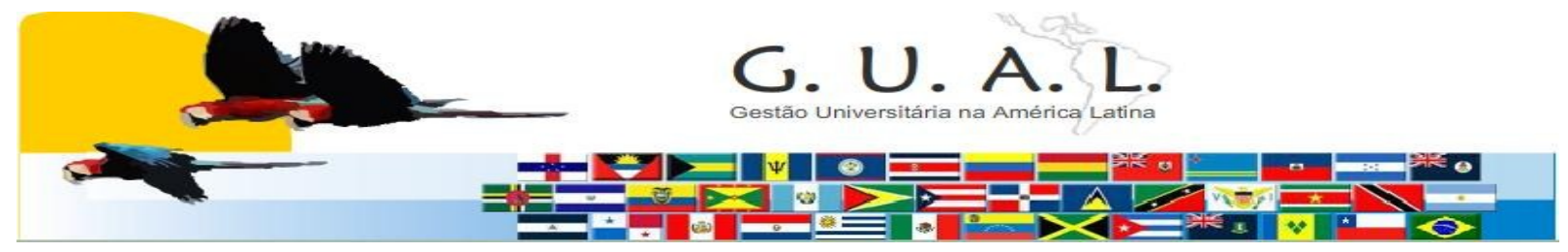

ISSN 1983-4535

\title{
O DESEMPENHO DAS UNIVERSIDADES PÚBLICAS PORTUGUESAS SEGUNDO SEUS ALUNOS: ANÁLISE DE EFICIÉNCIA POR MEIO DO DATA ENVELOPMENT ANALYSIS
}

\section{PERFORMANCE OF PORTUGUESE PUBLIC UNIVERSITIES BY THEIR STUDENTS: EFFICIENCY ANALYSIS THROUGH DATA ENVELOPMENT ANALYSIS}

\author{
Emerson Wagner Mainardes, Doutor \\ Universidade da Beira Interior - UBI \\ emerson.wm@sapo.pt \\ Helena Alves, Doutora \\ Universidade da Beira Interior - UBI \\ halves@ubi.pt \\ Mario Raposo, Doutor \\ Universidade da Beira Interior - UBI \\ mraposo@ubi.pt
}

Recebido em 16/novembro/2011

Aprovado em 04/abril/2012

Sistema de Avaliação: Double Blind Review

Esta obra está sob uma Licença Creative Commons Atribuição-Uso. 


\section{RESUMO}

O objetivo desta investigação foi avaliar o desempenho das Universidades Públicas Portuguesas, tomando por base as expectativas e satisfação de seus alunos e utilizando o método DEA (Data Envelopment Analysis). Para atingir o principal objetivo desta investigação, fez-se uma explicação dos conceitos fundamentais para uso do DEA, que mede a eficiência de uma organização ao comparar inputs e outputs. Em seguida, realizou-se uma pesquisa com 1.669 alunos de 55 faculdades de 11 Universidades Públicas Portuguesas, medindo-se os inputs (expectativa) e outputs (satisfação). Ao finalizar a análise dos dados, obteve-se as faculdades que demonstram uma boa relação entre a expectativa e satisfação dos alunos, o que pode auxiliar a melhoria da eficiência das faculdades tidas como ineficientes. Constatou-se que o porte da universidade não garante a eficiência. Independente do tamanho, a eficiência no atendimento das expectativas dos alunos pode ser alcançada e o porte da universidade não pode ser justificativa para a ineficiência relativa da organização. Além disso, constatou-se também que uma universidade pode ter faculdades eficientes e outras ineficientes. Portanto, ao invés de unir forças e crescer conjuntamente, determinadas universidades não seguem uma estratégia única, desperdiçando uma de suas principais forças, a capacidade de ser multidisciplinar perseguindo um objetivo único.

Palavras-chave: Gestão de universidades. Eficiência. Expectativa. Satisfação. Data Envelopment Analysis.

\section{ABSTRACT}

The objective of this investigation was to evaluate the performance of Portuguese Public Universities, based on the expectations and satisfaction of their students and using the DEA method (Data Envelopment Analysis). To achieve the main objective of this investigation, it was explained the fundamental concepts for the use of DEA, which measures the efficiency of an organization comparing inputs and outputs. Then, we carried out a survey of 1,669 students from 55 colleges from 11 Portuguese Public Universities, measuring inputs (expectation) and outputs (satisfaction). At the end of the data analysis, we obtained the colleges that demonstrate a good relationship between expectation and satisfaction of students, which can help improve the efficiency of colleges regarded as inefficient. It was found that the size of the university does not guarantee efficiency. Regardless of size, efficiency in meeting the expectations of students can be achieved and the size of the university can not be justification for the relative inefficiency of the organization. Moreover, it was also found that a university may have other efficient and inefficient colleges. So instead of joining forces and grow together, some universities do not follow a single strategy, wasting one of his main forces, the ability to be multidisciplinary pursuing a single goal.

Keywords: University management. Efficiency. Expectation. Satisfaction. Data Envelopment Analysis.

AGRADECIMENTOS: Esta pesquisa foi financiada pela FCT através do NECE - Núcleo de Investigação em Ciências Empresariais (Programa de Financiamento Plurianual das Unidades de I\&D da FCT - Fundação para a Ciência e Tecnologia, Ministério da Ciência, Tecnologia e Ensino Superior/Portugal) 


\section{INTRODUÇÃO}

Como pouco se observa na literatura atual avaliações de desempenho das universidades baseadas na satisfação das expectativas de seus alunos, um caminho para alcançar este objetivo passa por realizar análises comparativas de eficiência (Johnes, 2006). Este tipo de análise utiliza um conjunto de ferramentas matemáticas para avaliar comparativamente os resultados de um grupo de unidades tomadoras de decisão (Decision Making Unit ou DMU), estabelecendo fronteiras de eficiência entre as várias DMU's avaliadas (Shaw, 2009). Ou seja, define que as DMU's com melhor desempenho posicionamse como exemplos a serem seguidos pelas demais DMU's. Entre as ferramentas matemáticas mais usuais em análises de fronteira, destaca-se o DEA (Data Envelopment Analysis).

O DEA é uma ferramenta matemática surgida na década de 50 (Farrell, 1957) e operacionalizada nas décadas de 70 (Charnes, Cooper e Rhoder, 1978) e 80 (Banker, Charnes e Cooper, 1984), que se propôs a medir a eficiência de um processo, baseando-se, para isto, na análise de inputs e outputs não paramétricos de um determinado processo. Sendo inicialmente utilizada nas linhas de produção das empresas, e que na última década passou a fazer parte das ferramentas disponíveis para a realização de análises organizacionais, ao medir a eficiência de organizações (Zhu, 2009).

As análises de eficiência organizacional por meio do DEA vêm sendo realizadas, de modo geral, com inputs e outputs semelhantes (número de funcionários, faturamento, capacidade produtiva, número de pontos de vendas, entre outros), principalmente em empresas de serviços, onde a medição da eficiência produtiva envolve toda a empresa e os indivíduos relacionadas a ela (Shaw, 2009). Sua utilização principal tem sido o benchmarking, ao identificar as unidades que possuem maior eficiência sobre outras unidades, ou seja, os exemplos a serem seguidos por uma unidade considerada ineficiente (Zhu, 2009).

Já o construto satisfação tem sido uma variável bastante avaliada no meio organizacional (Grönroos, 2000), afinal representa o quanto a organização consegue atender às expectativas de seus consumidores ou usuários (Vargo e Lusch, 2004), especialmente na área dos serviços (Grönroos e Ojasalo, 2004). Tem demonstrado ser um importante fator para medir a qualidade dos outputs de uma organização, sejam eles produtos ou serviços (Anderson e Fornell, 2000). As vantagens da satisfação de consumidores são exaustivamente abordadas na literatura: melhor desempenho financeiro, retenção de clientes, competitividade, entre outros (Kotler, 2003), ou seja, um fator fundamental para qualquer organização. 
Tradicionalmente, a satisfação tem sido avaliada utilizando-se análises estatísticas tradicionais, como a regressão ou as equações estruturais, oferecendo caminhos para a tomada de decisão dos gestores organizacionais (Alves e Raposo, 2007). Porém, as análises de eficiência organizacional baseadas na satisfação dos stakeholders e utilizando o DEA, mostram-se raras na literatura.

Desta forma, a utilização do DEA para avaliar o desempenho organizacional sob o ponto de vista da satisfação dos stakeholders oferece uma perspectiva diferente das análises tradicionais deste construto, ao comparar unidades distintas (em tamanho, localização, quantidade de funcionários e consumidores, entre outros) que possuem os mesmos inputs e outputs. Sendo assim, o objetivo desta investigação foi avaliar o desempenho das Universidades Públicas Portuguesas, tomando por base as expectativas e satisfação de seus alunos e utilizando o método DEA.

O estudo justifica-se pela análise da eficiência organizacional baseada na satisfação dos consumidores ou usuários, sob um novo enfoque, diferente das tradicionais formas de avaliação da satisfação. Esta forma diferente de avaliar a organização pode oferecer soluções e oportunidades não obtidas nas análises tradicionais de satisfação.

Para atingir o principal objetivo desta investigação, inicialmente fez-se uma breve explicação dos conceitos fundamentais para uso do DEA e o próprio DEA. Em seguida, explicou-se os métodos de análise e, na sequência, analisou-se os resultados obtidos. Finalizase o estudo com as conclusões e recomendações da pesquisa realizada.

\section{CONCEITOS FUNDAMENTAIS DA ANÁLISE DE EFICIÊNCIA}

Para a realização de análises de eficiência, alguns conceitos se mostram fundamentais. Apesar dos conceitos de eficiência, eficácia, produtividade parecerem simples, diversas vezes causam confusão, como explicou Shaw (2009). Portanto, uma revisão destes conceitos mostra-se útil antes da realização da análise.

Segundo Banker e Morey (1986), todas as operações ou processos envolvem alguma transformação: acrescentam-se valores e mudam-se materiais para transformá-los em bens e/ou serviços que os clientes querem. Esta transformação envolve o uso de insumos, como trabalho, materiais, energia, máquinas e outros recursos, e geram produtos acabados, serviços, satisfação dos clientes e outros resultados. São estes fatores (inputs e outputs) que permitem aos gestores a avaliação da eficiência dos vários processos que resultam em uma medida de desempenho. Isto é, eliminar ou melhorar operações ineficientes diminui o custo dos insumos 
e aumenta a produtividade. A avaliação do desempenho de operações ajuda as organizações a se tornarem mais produtivas e eficientes.

A avaliação do desempenho é uma ferramenta importante de melhoria contínua para manter a competitividade e desempenha um papel importante no mundo organizacional, onde cada vez mais a concorrência é intensa e cresce a cada dia. Através da avaliação de desempenho, pode-se: revelar os pontos fortes e fracos das operações, atividades e processos da organização; preparar melhor a empresa para atender às necessidades de seus clientes; e identificar oportunidades para melhorar as operações e processos atuais, além de ajudar a criar novos produtos, serviços e processos (Youn e Park, 2009).

Porém, para boas avaliações de desempenho, há a necessidade de compreensão do que sejam eficácia, produtividade e eficiência, conceitos fundamentais para medir o desempenho de uma organização. Segundo Epstein e Henderson (1989), a eficácia está relacionada somente ao que é produzido, não levando em conta os recursos usados para a produção. Ou seja, é a capacidade de uma determinada unidade produtiva alcançar a produção que tinha como meta. Essa meta pode ter sido determinada pela própria unidade, bem como externamente. Mas isto não significa que tal unidade é produtiva ou mesmo eficiente.

Já a produtividade, para os mesmos autores, interessa-se pela razão entre o que foi produzido e o que foi gasto para que tal produção acontecesse. Portanto, o quociente entre estes dois fatores indica a produtividade de uma determinada unidade. E eficiência é um conceito relativo, que compara o que foi produzido, considerando os recursos disponíveis, com o que poderia ter sido produzido com os mesmos recursos. Isto é, compara a produtividade ideal com a produtividade real. Mais precisamente é a combinação ótima dos inputs (insumos e métodos necessários) no processo de produção para que resulte no máximo de outputs (produtos). Ou seja, procura minimizar a relação insumos e produtos, assegurando a otimização da utilização dos recursos (Epstein e Henderson, 1989). É um conceito que se relaciona com os meios e não com os fins.

Para avaliar a eficiência entre DMU's (Decision Making Units), há métodos paramétricos (exigem uma parametrização da relação funcional entre os recursos e o que é produzido, ou seja, a mesma unidade de medida) ou não-paramétricos (não consideram a mesma unidade de medida). Como exemplo deste segundo, pode-se avaliar a eficiência de uma universidade pelo número de alunos, número de professores, número de publicações, número de patentes, entre outros. Todas estas variáveis são medidas de modo diferente, porém podem ser analisadas em conjunto em análises não-paramétricas (Johnes, 2006). 
É preciso compreender que, para Grönroos e Ojasalo (2004), os serviços, devido a sua natureza, requerem análises de eficiência não-paramétricas. E esta tem sido a realidade do serviço educacional em nível superior. Diversos estudos (por exemplo, Scheerens, 2000, Johnes, 2006, Youn e Park, 2009, Kantabutra e Tang, 2010) consideram a análise de eficiência das universidades com medidas não-paramétricas, porém nenhum deles o fez sob a perspectiva da satisfação dos alunos. Grande parte dos estudos sobre a temática ensino superior avalia a eficiência das universidades a partir de preenchimento de vagas existentes, alunos formados, número de professores, faturamento, entre outros, sem mencionar as percepções dos alunos, conforme orientam Grönroos e Ojasalo (2004), que consideraram a perspectiva do usuário do serviço como fundamental na mensuração da eficiência de uma organização de serviços, que é o caso da universidade.

Além disso, também é preciso compreender que a eficiência deriva-se em duas: a eficiência técnica e a eficiência econômica. A primeira, de acordo com Shaw (2009), significa empregar o menor nível possível de insumos para produzir um nível dado de produção, ou quando se obtém o maior nível possível de produção com um dado nível de insumos. Quando há mais de um produto, o produtor é eficiente para uma determinada quantidade de insumos se conseguir aumentar a produção de um produto sem diminuir a produção de outro.

Já a eficiência econômica refere-se a conseguir produzir mais produtos com o mesmo custo, ou reduzir os custos mantendo a mesma produção. Estes dois tipos são relacionados, ou seja, para se obter eficiência econômica, é preciso alcançar a eficiência técnica (Shaw, 2009). Porém, em situações onde as questões econômicas são contraditórias, como é o caso das universidades públicas, a eficiência técnica ganha importância e tem sido o meio de avaliação do desempenho deste tipo de organização. No caso das universidades, esta eficiência técnica é relacionada a uma medida de eficiência social (Scheerens, 2000), ou seja, a capacidade da universidade em cumprir sua missão.

\subsection{Análise de eficiência e o DEA}

Segundo Cooper, Seiford e Tone (2000), há uma preocupação crescente com a mensuração e comparação da eficiência de unidades organizacionais, como escolas, hospitais, lojas, agências bancárias e outros casos semelhantes, onde há um conjunto relativamente homogêneo de unidades. Para os autores, a medida usual de eficiência (razão entre outputs e inputs) é, muitas vezes, insuficiente devido à existência de múltiplas entradas e saídas relacionadas com diferentes recursos, atividades e fatores ambientais. 
Com dois inputs e três outputs, a dificuldade de comparar a eficiência se torna aparente. Ou seja, diferentes padrões de níveis de atividade são suportados por diferentes quantidades de recursos. Neste caso, fazer comparações de eficiência não é tão simples. Foi para resolver este problema que surgiu o DEA. De acordo com Charnes, Cooper e Rhodes (1978), o DEA é uma técnica de programação linear que visa medir o desempenho relativo de unidades organizacionais onde a presença de múltiplos inputs e outputs torna as comparações difíceis. De modo geral, o DEA tem sido utilizado para estimar a utilização ótima de inputs, a produtividade, a identificação de grupos estratégicos, a determinação de pontos de referência e programas de gestão da qualidade total, a estimativa dos custos sociais e privados de regulação e a capacidade de outputs indesejáveis (Kirkley et al., 2001).

A mensuração da eficiência relativa que considera múltiplos inputs e outputs foi primeiro tratada por Farrell (1957), sendo posteriormente desenvolvida por Farrell e Fieldhouse (1962). No desenvolvimento matemático destes autores, eles se focalizaram na construção de uma unidade hipotética eficiente, que era resultado da média ponderada de unidades eficientes, para servir de comparação com uma ou mais unidades ineficientes. Portanto a fórmula base era a razão entre a soma ponderada dos outputs e a soma ponderada dos inputs. A hipótese inicial para este modelo é que esta medida de eficiência requer um conjunto comum de pesos para ser aplicado em todas as unidades. Isto imediatamente levanta o problema da forma como tal conjunto de pesos pode ser obtida, o que levanta dúvidas sobre a metodologia dos autores. Esta medida de eficiência acoplada ao pressuposto de que um único conjunto de pesos é necessário é, portanto, insatisfatória.

Foi por esta questão que surgiu o DEA. Charnes, Cooper e Rhodes (1978) reconheceram a dificuldade na busca de um conjunto comum de pesos para determinar a eficiência relativa. Eles reconheceram a legitimidade da proposta, que pode avaliar as unidades em termos de múltiplas e diferentes entradas e saídas (não-paramétrico), e, portanto, a necessidade de se adotar pesos diferentes. Desta forma, os autores propuseram que cada unidade deve adotar um conjunto de pesos mais favorável para a comparação com as outras unidades. Essa flexibilidade na escolha dos pesos é tanto uma fraqueza quanto uma vantagem desta abordagem. É uma fraqueza porque a escolha criteriosa dos pesos por unidade, possivelmente relacionada com o valor de qualquer input ou output pode permitir que uma unidade pareça eficiente, mas pode haver a preocupação de que isso tem mais a ver com a escolha dos pesos do que com o rendimento da própria unidade. Esta flexibilidade é também 
uma força, no entanto, quando uma unidade torna-se ineficiente, mesmo quando os pesos mais favoráveis foram incorporados na sua medida de eficiência (Fandel, 2007).

Neste sentido, o DEA pode ser apropriado onde as unidades possuam inputs ou outputs variados, ou quando existe um elevado grau de incerteza ou discordância sobre o valor de algumas entradas ou saídas (como é o caso das percepções das pessoas). Diferente de outras metodologias, o DEA é uma metodologia voltada para as fronteiras, e não para uma tendência central, como são as regressões. Devido a esta perspectiva, o DEA mostra habilidade em descobrir relações que permanecem escondidas em outros métodos, afinal o DEA lida com múltiplas entradas e saídas, diferente da regressão, que lida somente com um output de cada vez (Sarrico e Dyson, 2000).

Segundo Zhu (2009), o DEA funciona da seguinte forma: cada uma das DMU's escolhidas utiliza múltiplas entradas para produzir múltiplas saídas. Com base nas informações existentes sobre as entradas e as saídas, as possibilidades de produção são especificadas. O conjunto de possibilidades de produção consiste em todas as combinações possíveis de entradas e saídas, podendo ser contínua ou discreta. Uma parte específica do conjunto de possibilidades de produção é chamada de fronteira eficiente. Se a DMU está na fronteira eficiente, ela é referida como uma unidade eficiente, caso contrário ela é considerada ineficiente. O DEA oferece índices de eficiência e um conjunto de referência para as DMU's ineficientes. Os escores de eficiência representam um grau de eficiência de cada DMU. O conjunto de referência para as unidades ineficientes consiste de um conjunto de unidades eficientes e determina uma unidade alvo virtual na fronteira eficiente. Ou seja, a unidade de destino é encontrada ao se projetar uma DMU ineficiente à superfície eficiente. Isto é, o DEA serve para verificar a eficiência de uma unidade e para encontrar o conjunto de referência e o escore de eficiência para as unidades ineficientes. Portanto, a técnica DEA também oferece um ponto de referência para melhorar o desempenho das unidades ineficientes por uma expansão da produção de resultados ou a redução do consumo de insumos, dependendo do objetivo da análise (Johnes, 2006).

Um exemplo, demonstrado por Kantabutra e Tang (2010), de análise de eficiência através de um modelo orientado para produção para quatro DMU's (A, B, C, D) que utilizam um input para a produção de dois outputs (Y1, Y2) é apresentado na figura 1. Nesta figura, a fronteira de eficiência é derivada da DMU que pode produzir o nível máximo de resultados com o atual nível de entrada, que são DMU's A e B. Estas duas DMU's são consideradas eficientes ou que possuem as melhores práticas. Por outro lado, DMU's C e D, que não se 
encontram na fronteira, são as unidades que produzem resultados menores com a mesma quantidade de insumos, em comparação com DMU's A e B. As DMU's C e D são, portanto, relativamente ineficientes. Nesta abordagem, as unidades eficientes ou ineficientes são consideradas relativas, pois elas são medidas comparativamente com outras DMU's. Além disso, se qualquer DMU for excluída do estudo, a fronteira eficiente pode mudar.

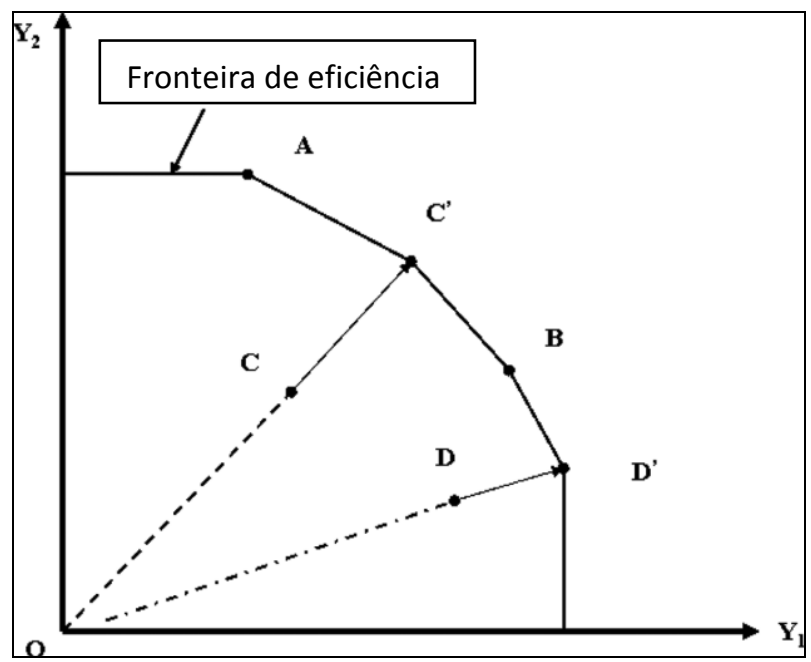

FIGURA 1 Exemplo de fronteira de eficiência Fonte: Kantabutra e Tang (2010, p. 22)

O escore de eficiência é calculado por uma relação entre a distância de onde se encontra uma DMU individual e a distância do local onde é suposto ser eficiente. Neste exemplo, os escores de eficiência das DMU's A e B são iguais a 1, já que ambos se encontram na fronteira eficiente. O escore de eficiência da DMU C é OC/OC' e da DMU D é OD/OD'. Assim, os escores de eficiência das unidades ineficientes, C e D neste exemplo, são menores que 1. Para ser mais específico, os escores de eficiência da DMU em análise são os números reais, que vão 0-1. As razões de OC/OC' e OD/OD' também representam o potencial de incremento proporcional nos outputs das DMU's C e D, utilizando o nível a mesma quantidade de inputs, tornando-as eficientes (Kantabutra e Tang, 2010).

Portanto, de acordo com Zhu (2009), o DEA determina a curva de eficiência empírica, também conhecida como isoquanta (que representa uma função onde para todas as combinações de insumos obtém-se uma quantidade ótima de produto, ou seja, a relação entre inputs e outputs), por meio de programação matemática de otimização, não exigindo nenhuma relação funcional entre os insumos e os produtos. Considerando este aspecto, tal técnica é bastante susceptível às observações extremas e aos erros de medidas. 
Resumidamente, o DEA estabelece fronteiras de eficiência, ao comparar o desempenho de várias DMU's. Essa ferramenta possibilita analisar o desempenho relativo de DMU's, que utilizam os mesmos tipos de insumos para produzir os mesmos bens e/ou serviços. Tanto os produtos quanto os insumos podem ser variáveis contínuas, ordinais ou categóricas. Além disso, podem ser medidas em diferentes unidades, afinal é um método não paramétrico (Banker e Maindiratta, 1986).

Logo que surgiu o DEA, o modelo proposto por Charnes, Cooper e Rhodes (1978), tradicionalmente chamado de CCR, estabeleceu uma análise com retornos constantes de escala (CRS/Constant Returns to Scale), que estabelece uma relação proporcional entre inputs e outputs, semelhante à regressão. Anos depois, Banker, Charnes e Cooper (1984) consideraram retornos variáveis de escala (VRS/Variable Returns to Scale), sendo conhecido por BCC. Neste caso, a relação entre inputs e outputs não é linear, mas sim convexa.

Estes são os dois modelos básicos de DEA, o CCR (ou CRS) e o BCC (ou VRS). Ambos podem ser desenhados sob duas formas de maximizar a eficiência (Banker, Charnes e Cooper, 1984): Para redução do consumo de insumos, mantendo o nível de produção (orientação ao insumo); Aumentar a produção, mantendo os níveis de insumos (orientação ao produto).

O resultado da aplicação do método estabelece as melhores práticas observadas $(100 \%$ de eficiência relativa) e formam a fronteira eficiente com as unidades virtuais ou fictícias. Desta forma, a eficiência de outras DMU's analisadas é mensurada a partir das posições relativas por elas, ocupadas em relação à fronteira. Por exemplo, se o coeficiente encontrado é 0,80 e o modelo é o CCR (retorno constante de escala), isto indicará que essa DMU pode reduzir o consumo de insumos (sem reduzir sua produção) em $20 \%$ para ser eficiente (orientação para insumos). Se a orientação fosse para os produtos, o índice seria 1,25 (1/0,80), que significa que a DMU poderia produzir mais $25 \%$ de produtos com os insumos que utiliza. Já se o retorno de escala fosse variável (modelo BCC), este cálculo não seria tão simples, pois enquanto no CCR a fronteira de eficiência é composta por retas, no BCC, a fronteira é uma curva convexa. Neste caso, o BCC forma uma fronteira convexa eficiente com as melhores DMU's, admitindo que a eficiência máxima varie em função da economia de escala, algo que possibilita a comparação entre DMU's de portes distintos (Avkiran, 2001).

A abordagem DEA para a medição da eficiência gerencial gera subprodutos úteis. Além de desenvolver avaliações de eficiência relativas para cada DMU, os modelos de eficiência podem fornecer informações sobre o que é necessário fazer para ajustar uma DMU 
ineficiente (Banker e Morey, 1986). Em resumo, o quadro 1 sistematiza as forças e limitações do DEA.

\begin{tabular}{|c|c|}
\hline do DEA & Limitações do DEA \\
\hline Trata de múltiplos inputs e outputs & $\begin{array}{l}\text { Exige DMU's homogêneas (desempenham as } \\
\text { mesmas atividade e possuem objetivos comuns) }\end{array}$ \\
\hline Não exige parametrização das variáveis & $\begin{array}{l}\text { Testes estatísticos de hipóteses são difíceis de } \\
\text { realizar, pois é um método não-estatístico }\end{array}$ \\
\hline $\begin{array}{l}\text { Mede eficiência relativa, por comparações com } \\
\text { pares }\end{array}$ & $\begin{array}{l}\text { Erros de medição causam sérios problemas nos } \\
\text { resultados (maiores que em outros métodos) }\end{array}$ \\
\hline Não exige relação funcional entre inputs e outputs & $\begin{array}{l}\text { Exige compreensão matemática para interpretar } \\
\text { análises }\end{array}$ \\
\hline $\begin{array}{l}\text { Constrói fronteira eficiente (empírica) sem } \\
\text { precisar estabelecer ponderações }\end{array}$ & $\begin{array}{l}\text { É sensível à escolhas arbitrárias de variáveis, } \\
\text { podendo-se inserir variáveis não importantes nos } \\
\text { processo (distorcendo os resultados) }\end{array}$ \\
\hline $\begin{array}{l}\text { Indica } \\
\text { melho }\end{array}$ & \multirow{2}{*}{$\begin{array}{l}\text { Não mede eficiência absoluta, pois considera que } \\
\text { a DMU com melhor relação entre inputs e outputs } \\
\text { é eficiente (mesmo que não tenha atingido suas } \\
\text { máximas possibilidades) }\end{array}$} \\
\hline $\begin{array}{l}\text { Pode identificar configurações alternativas de } \\
\text { insumos para se obter resultados mais elevados }\end{array}$ & \\
\hline $\begin{array}{l}\text { sem necessariamente aumentar a utilização total } \\
\text { dos recursos }\end{array}$ & \multirow{2}{*}{$\begin{array}{l}\text { Por causa de sua natureza determinística, é } \\
\text { sensível a erros de medida (não faz distinção } \\
\text { entre ineficiência técnica e efeitos de ruídos } \\
\text { estatísticos) }\end{array}$} \\
\hline & \\
\hline & \multirow{2}{*}{$\begin{array}{l}\text { Exige um número de DMU's superior ao número } \\
\text { de variáveis, pois poucas DMU's não são bem } \\
\text { discriminadas pelo DEA }\end{array}$} \\
\hline $\begin{array}{l}\text { Revela relações entre variáveis não obse } \\
\text { em outros métodos }\end{array}$ & \\
\hline
\end{tabular}

QUADRO 1 Forças e limitações do DEA

Fonte: adaptado de Zhu (2009, p.74)

\section{METODOLOGIA E ESTRUTURA DA ANÁLISE}

De acordo com Shaw (2009), o uso do DEA exige uma seqüência de passos. Primeiro, escolhem-se as DMU's. Em seguida, avalia-se o processo produtivo das DMU's analisadas para identificar e classificar os insumos e produtos, para, na sequência, coletar os dados, escolher um método e realizar as análises. É importante considerar que as DMU's escolhidas devem ser homogêneas, ou seja, produzir os mesmos bens e serviços, utilizando insumos iguais. Já com relação ao número de unidades, quanto maior a quantidade de DMU's analisadas, maior será a capacidade de discriminação do modelo.

\subsection{Definição e Seleção de DMU's}

Conforme orienta Zhu (2009), o grupo de DMU's a ser adotado na análise tem de ter a mesma utilização de inputs e outputs, variando apenas em intensidade. O grupo precisa ser 
homogêneo, ou seja, deve realizar as mesmas tarefas, perseguindo os mesmos objetivos, trabalhando nas mesmas condições de mercado e sendo autônomo na tomada de decisões.

Considerando estes fatores, a escolha recaiu sobre a análise comparativa entre as Universidades Públicas Portuguesas. Como o DEA realiza comparações entre DMU's, no intuito de encontrar as que são eficientes (ou que possuem melhores práticas), uma análise comparativa pode retratar o panorama atual da satisfação dos alunos das Universidades Públicas Portuguesas. O objetivo aqui foi encontrar as DMU's que melhor satisfazem seus estudantes, ao comparar as suas expectativas com a sua satisfação atual.

Porém, uma análise considerando as 11 Universidades Públicas Portuguesas pode não discriminar bem as diferenças entre elas. Para obterem-se resultados mais reveladores, os alunos foram divididos entre universidades e, dentro delas, entre cinco faculdades distintas, conforme o seu curso: cursos das ciências sociais (cursos como gestão, economia, sociologia, direito, entre outros), cursos das ciências médicas (medicina, farmácia, veterinária, entre outros), cursos das ciências básicas (matemática, física, química, entre outros), cursos de engenharia (engenharias, tecnologias e cursos correlatos), cursos de artes e letras (ciências da comunicação, filosofia, letras, entre outros). Com esta separação, obteve-se 55 DMU's (11 x 5), número este capaz de discriminar as melhores práticas que levam à satisfação dos alunos entre universidades/faculdades, retratando melhor a diferença entre as várias áreas das Universidades Públicas Portuguesas.

\subsection{Seleção de Variáveis}

Zhu (2009) explica que a escolha das variáveis de inputs e outputs deve ser feita criteriosamente a partir de uma lista de possíveis variáveis ligadas às DMU's. Porém, há a possibilidade de um grande número de DMU's posicionarem-se na fronteira estabelecida, algo que reduz a capacidade do DEA em discriminar DMU's eficientes de ineficientes. Portanto, é preciso buscar um ponto de equilíbrio na quantidade de DMU's e variáveis, com vistas a ampliar o poder discriminatório do DEA, o que pode exigir a inserção ou exclusão de variáveis durante o processo de análise.

A literatura mostra que o DEA diversas vezes foi utilizado para avaliar o ensino superior (por exemplo, Sarrico e Dyson, 2000, Johnes, 2006, Youn e Park, 2009, Kantabutra e Tang, 2010). Porém, nenhum dos estudos avaliados fez a avaliação de eficiência de universidades baseado na satisfação dos alunos, sendo este um diferencial desta investigação. Por outro lado, avaliar eficiência de DMU's considerando a satisfação de consumidores já foi 
realizada com outros objetos de estudo, como em bancos e supermercados, conforme demonstrou Cooper, Seiford e Tone (2006). Desta forma, a escolha dos inputs e outputs concentrou-se exclusivamente nas percepções dos alunos, não sendo levados em conta outros fatores, como o número de vagas existentes, o número de alunos por universidade, o número de professores, publicações, patentes, saídas profissionais, entre outros. Portanto, os fatores medidos envolveram as expectativas e satisfação gerais dos alunos, bem como três fatores específicos identificados por Mainardes, Alves e Domingues (2009) como as principais demandas dos alunos: grau de exigência do curso, realização pessoal e ambiente da universidade.

Desta forma os inputs escolhidos foram as notas médias obtidas por DMU para a:

- Expectativas dos alunos com relação às suas principais demandas (grau de exigência do curso, ambiente da universidade e realização pessoal);

- Expectativa geral dos alunos com relação ao curso;

- Expectativa geral dos alunos com relação à universidade.

Já os outputs foram as notas médias obtidas por DMU para a:

- Satisfação dos alunos com relação às suas principais demandas (grau de exigência do curso, ambiente da universidade e realização pessoal);

- Satisfação geral dos alunos com relação ao curso;

- Satisfação geral dos alunos com relação à universidade.

Por fim, considerando as escolhas realizadas, a análise foi composta por 5 inputs e 5 outputs. Tendo em consideração que foram 55 as DMU's, a validez da análise pode ser confirmada pela fórmula definida por Avkiran (1999), que deduziu matematicamente que o resultado da razão entre o número de DMU's sobre a multiplicação entre o número de inputs e outputs deve ser superior a 1,333 ( $\mathrm{N}^{\circ} \mathrm{DMU}$ 's/( $\mathrm{N}^{\circ}$ inputs* $\mathrm{N}^{\circ}$ outputs)). Para o caso em questão, o indicador ficou em 2,20, o que valida a análise de DEA realizada aqui.

\subsection{Coleta dos dados}

Tendo sido definidos as DMU's, os inputs e os outputs, foi desenvolvido um questionário on-line específico para a obtenção dos dados necessários para a realização da análise. $\mathrm{O}$ questionário continha dez perguntas, cinco referentes às expectativas (expectativas quanto à exigência do curso, à realização pessoal, ao ambiente da universidade, ao curso e à universidade) e cinco referentes à satisfação (satisfação quanto à exigência do curso, à 
realização pessoal, ao ambiente da universidade, ao curso e à universidade). Cada questão tinha cinco opções de resposta (escala Likert, ver Hair Jr. et al., 2003), que correspondia a nenhuma expectativa a muito alta expectativa ou muito insatisfeito a muito satisfeito (conforme a questão). Depois das dez questões, o aluno informava sua universidade, o curso que frequenta e a faculdade que o curso pertence.

Após a realização de um pré-teste, o questionário foi considerado pronto para ser aplicado. Em seguida, fez-se o envio do inquérito para todos os alunos de 11 Universidades Públicas Portuguesas (129.534 alunos), via email, em 29 de abril de 2010. Os inquéritos foram recebidos no período de 29 de abril a 21 de maio. Após esta data, fez-se a avaliação dos dados coletados, tentando identificar algum viés nas respostas, ou mesmo falhas/problemas no preenchimento dos questionários devolvidos. Dos 1.832 inquéritos recebidos, 1.669 foram considerados válidos.

\subsection{Escolha do Modelo}

Como comentado anteriormente, o DEA utiliza dois modelos: o CCR e o BCC. A diferença entre ambos, basicamente, é considerar os retornos de escala, que podem ser constantes (CCR) ou variáveis (BCC). A escolha do modelo deve seguir alguns critérios (Charnes et al., 1994): as propriedades implícitas dos retornos de escala; o desenho geométrico da superfície de envelopamento dos dados, relacionado com as medidas de eficiência; e as projeções de eficiência, isto é, o caminho das DMU's ineficientes até a fronteira de eficiência.

A DMU virtual das unidades ineficientes é determinada pela projeção da DMU real na fronteira de eficiência, sendo que a forma de como é feita tal projeção é que determina a orientação do modelo (Shaw, 2009): orientação a inputs (quando a eficiência é atingida por uma redução de inputs, mantidos os outputs constantes) e orientação a outputs (quando se deseja maximizar os outputs sem diminuir os inputs).

Considerando estes dois aspectos, para a análise aqui realizada, optou-se pelo BCC, com orientação para os outputs. A escolha do BCC deve-se ao fato de as percepções dos alunos não serem necessariamente constantes, mas sim variáveis, especialmente nos extremos (total insatisfação ou total satisfação). A curva de percepções dos alunos é semelhante a um "S" e não a uma reta, como demonstrou Garver (2003). Já a orientação aos outputs parece mais óbvia. O objetivo é ampliar a satisfação (e não reduzir as expectativas iniciais), pois é a 
variável que a universidade tem poder de gestão. Por fim, considerando as explicações apresentadas, iniciou-se o processo de análise.

\section{ANÁLISE DOS DADOS}

A análise dos dados, com o objetivo de avaliar o desempenho das Universidades Públicas Portuguesas baseado na satisfação de seus alunos, foi desenvolvida da seguinte forma: apresentação dos dados para análise, análise de eficiência das DMU's tendo as expectativas como inputs e satisfação como outputs, obtidos junto aos alunos. Estas análises permitiram encontrar as DMU's que são mais eficientes, ou seja, que estão na fronteira de eficiência relativa (melhor desempenho comparado com as demais DMU's), estabelecendo um panorama geral do desempenho das Universidades Públicas Portuguesas conforme a satisfação de seus alunos.

\subsection{Dados para análise}

Como já explicado, foram selecionadas 55 DMU's, 5 inputs e 5 outputs. Sendo assim, a tabela 1 apresenta os dados para análise.

Observando-se a tabela 1, primeiramente percebe-se que sete DMU's foram excluídas da análise. Apesar de o DEA ser uma análise que exige somente que as DMU's sejam homogêneas (neste caso, as faculdades que pertencem às universidades, e que são regidas pela mesma legislação e seguem princípios similares) e que todas as DMU's utilizem os mesmos inputs e outputs (nesta situação, as percepções dos próprios alunos das faculdades quanto à expectativa e satisfação), independente da intensidade, decidiu-se por excluir DMU's com um número muito baixo de casos.

Esta decisão deve-se principalmente à preocupação de uma DMU ser considerada eficiente por um número muito pequeno de alunos. Quanto ao DEA, o tamanho de cada amostra não impede a análise, afinal é um método não-estatístico e que não define eficiências absolutas, mas sim relativas (comparadas). 
TABELA 1 Dados para a análise DEA

\begin{tabular}{|c|c|c|c|c|c|c|c|c|c|c|c|}
\hline Universidade & DMU & $\begin{array}{c}\text { Média } \\
\text { Expec. } \\
\text { Exig. } \\
\text { (MEE) }\end{array}$ & $\begin{array}{l}\text { Média } \\
\text { Expec. } \\
\text { Realiz. } \\
\text { (MER) }\end{array}$ & $\begin{array}{c}\text { Média } \\
\text { Expec. } \\
\text { Amb. } \\
\text { (MEA) }\end{array}$ & $\begin{array}{l}\text { Média } \\
\text { Expec. } \\
\text { Curso } \\
\text { (MEC) }\end{array}$ & $\begin{array}{c}\text { Média } \\
\text { Expec. } \\
\text { Univ. } \\
\text { (MEU) }\end{array}$ & $\begin{array}{c}\text { Média } \\
\text { Satis. Exig. } \\
\text { (MSE) }\end{array}$ & $\begin{array}{l}\text { Média } \\
\text { Satis. } \\
\text { Realiz. } \\
\text { (MSR) }\end{array}$ & $\begin{array}{l}\text { Média } \\
\text { Satisf. } \\
\text { Amb. } \\
\text { (MSA) }\end{array}$ & $\begin{array}{l}\text { Média } \\
\text { Satisf. } \\
\text { Curso } \\
\text { (MSC) }\end{array}$ & $\begin{array}{c}\text { Média } \\
\text { Satisf. } \\
\text { Univ. } \\
\text { (MSU) }\end{array}$ \\
\hline \multirow{5}{*}{$\begin{array}{c}\text { Universidade do } \\
\text { Algarve }\end{array}$} & UAlg_CS & 3,95 & 4,18 & 4,23 & 4,14 & 4,18 & 3,82 & 4,00 & 4,36 & 4,00 & 4,05 \\
\hline & UAlg_CM & 3,91 & 4,18 & 4,36 & 3,73 & 3,55 & 3,45 & 3,45 & 3,82 & 3,55 & 3,45 \\
\hline & UAlg_CB & Excl. & -- & -- & -- & -- & -- & -- & -- & -- & -- \\
\hline & UAlg_Eng & 4,00 & 4,13 & 4,07 & 3,80 & 3,87 & 3,67 & 3,87 & 4,40 & 3,80 & 4,13 \\
\hline & UAlg_AL & Excl. & -- & -- & -- & -- & -- & -- & -- & -- & -- \\
\hline \multirow{5}{*}{$\begin{array}{c}\text { Universidade dos } \\
\text { Açores }\end{array}$} & UAc CS & 3,85 & 4,38 & 4,39 & 3,72 & 3,41 & 3,49 & 3,74 & 3,99 & 3,62 & 3,56 \\
\hline & UAc_CM & 3,68 & 4,27 & 4,36 & 4,05 & 3,59 & 3,86 & 3,91 & 4,09 & 3,95 & 3,27 \\
\hline & UAc_CB & 4,00 & 4,70 & 3,80 & 4,00 & 3,70 & 3,50 & 4,10 & 4,20 & 3,60 & 3,20 \\
\hline & UAc_Eng & 4,07 & 4,25 & 4,50 & 3,93 & 3,46 & 3,39 & 3,50 & 3,57 & 3,50 & 3,21 \\
\hline & UAc_AL & 3,83 & 3,83 & 4,39 & 3,70 & 3,52 & 3,52 & 3,52 & 3,78 & 3,35 & 3,43 \\
\hline \multirow{5}{*}{$\begin{array}{l}\text { Universidade da } \\
\text { Beira Interior }\end{array}$} & UBI_CS & 4,00 & 4,46 & 4,21 & 3,91 & 3,57 & 3,84 & 4,09 & 4,16 & 4,03 & 3,90 \\
\hline & UBI_CM & 4,25 & 4,81 & 4,81 & 3,81 & 3,19 & 3,94 & 3,94 & 4,19 & 3,88 & 3,94 \\
\hline & UBI_CB & 4,33 & 4,25 & 4,17 & 3,67 & 3,50 & 4,00 & 4,00 & 4,08 & 3,75 & 3,75 \\
\hline & UBI_Eng & 4,00 & 4,20 & 4,42 & 3,94 & 3,40 & 3,40 & 3,46 & 3,96 & 3,42 & 3,16 \\
\hline & UBI_AL & 3,78 & 3,83 & 4,11 & 3,72 & 3,33 & 3,78 & 4,06 & 4,17 & 3,89 & 3,56 \\
\hline \multirow{5}{*}{$\begin{array}{l}\text { Universidade de } \\
\text { Coimbra }\end{array}$} & UC_CS & 4,44 & 4,20 & 4,20 & 4,04 & 4,04 & 3,44 & 3,72 & 3,92 & 3,08 & 3,32 \\
\hline & $\mathrm{UC} C \mathrm{CM}$ & 4,50 & 4,75 & 4,25 & 4,00 & 4,00 & 3,75 & 3,50 & 4,25 & 3,33 & 3,58 \\
\hline & $\mathrm{UC} \mathrm{CB}$ & 4,24 & 4,64 & 4,52 & 3,76 & 3,84 & 3,84 & 3,68 & 4,20 & 3,72 & 4,08 \\
\hline & UC_Eng & 4,14 & 4,42 & 4,37 & 4,03 & 4,08 & 3,73 & 3,66 & 4,20 & 3,81 & 4,00 \\
\hline & $\mathrm{UC} \mathrm{AL}$ & Excl. & -- & -- & -- & -- & -- & -- & -- & -- & -- \\
\hline \multirow{5}{*}{$\begin{array}{l}\text { Universidade de } \\
\text { Évora }\end{array}$} & UEvora_CS & 4,11 & 4,47 & 4,31 & 3,71 & 3,82 & 3,64 & 3,96 & 3,96 & 3,67 & 3,42 \\
\hline & UEvora_CM & 4,60 & 4,80 & 4,60 & 4,10 & 3,60 & 3,80 & 4,30 & 4,30 & 4,10 & 3,80 \\
\hline & UEvora_CB & 4,11 & 4,44 & 4,44 & 3,63 & 3,44 & 3,67 & 3,74 & 4,26 & 3,74 & 3,48 \\
\hline & UEvora Eng & 4,12 & 4,38 & 4,23 & 3,88 & 3,77 & 3,73 & 3,65 & 3,92 & 3,46 & 3,23 \\
\hline & UEvora_AL & 4,09 & 4,36 & 3,73 & 3,91 & 3,64 & 3,45 & 4,00 & 3,82 & 4,00 & 3,45 \\
\hline \multirow{5}{*}{$\begin{array}{c}\text { Universidade de } \\
\text { Lisboa }\end{array}$} & $\mathrm{UL} \mathrm{CS}$ & 4,22 & 4,25 & 4,07 & 3,90 & 3,86 & 3,81 & 4,02 & 4,12 & 3,78 & 3,76 \\
\hline & $\mathrm{UL}$ CM & 4,21 & 4,07 & 4,14 & 4,00 & 3,43 & 3,64 & 3,50 & 3,79 & 3,36 & 3,36 \\
\hline & UL_CB & 4,38 & 4,54 & 4,46 & 4,08 & 4,31 & 3,69 & 4,00 & 3,54 & 3,77 & 3,77 \\
\hline & UL_Eng & 4,00 & 4,25 & 4,58 & 3,50 & 3,92 & 3,75 & 3,83 & 4,50 & 4,00 & 4,00 \\
\hline & UL_AL & 4,32 & 4,65 & 4,42 & 4,00 & 3,84 & 3,55 & 3,61 & 3,97 & 3,26 & 3,35 \\
\hline
\end{tabular}


O DESEMPENHO DAS UNIVERSIDADES PÚBLICAS PORTUGUESAS SEGUNDO SEUS ALUNOS: ANÁLISE DE EFICIÊNCIA POR MEIO DO DATA ENVELOPMENT ANALYSIS

\begin{tabular}{|c|c|c|c|c|c|c|c|c|c|c|c|}
\hline \multirow{5}{*}{$\begin{array}{l}\text { Universidade da } \\
\text { Madeira }\end{array}$} & UMa_CS & 4,04 & 4,55 & 4,43 & 3,79 & 3,66 & 3,56 & 3,65 & 3,87 & 3,40 & 3,49 \\
\hline & UMa_CM & 3,80 & 4,40 & 4,30 & 4,20 & 3,30 & 4,20 & 4,10 & 4,10 & 4,10 & 3,60 \\
\hline & UMa_CB & 3,93 & 4,64 & 4,50 & 3,79 & 3,36 & 3,86 & 4,00 & 4,21 & 3,71 & 3,93 \\
\hline & UMa_Eng & 3,76 & 4,20 & 4,40 & 3,52 & 3,32 & 3,28 & 3,32 & 3,44 & 3,20 & 3,16 \\
\hline & UMa_AL & 4,00 & 3,33 & 4,17 & 3,92 & 3,67 & 3,83 & 3,75 & 3,75 & 3,75 & 3,75 \\
\hline \multirow{5}{*}{$\begin{array}{l}\text { Universidade do } \\
\text { Minho }\end{array}$} & UMinho_CS & 4,36 & 4,34 & 4,43 & 3,98 & 3,81 & 3,70 & 3,75 & 4,13 & 3,74 & 3,75 \\
\hline & UMinho_CM & 4,45 & 4,36 & 4,36 & 4,00 & 3,91 & 3,73 & 4,00 & 4,27 & 3,91 & 3,91 \\
\hline & UMinho_CB & 3,92 & 4,50 & 4,67 & 3,75 & 3,75 & 4,25 & 3,83 & 4,33 & 3,67 & 4,08 \\
\hline & UMinho_Eng & 4,00 & 4,27 & 4,18 & 4,09 & 3,82 & 3,82 & 3,45 & 4,00 & 3,55 & 3,55 \\
\hline & UMinho_AL & 4,80 & 4,50 & 4,20 & 4,50 & 4,40 & 2,30 & 2,00 & 2,90 & 1,80 & 1,60 \\
\hline \multirow{5}{*}{$\begin{array}{c}\text { Universidade Nova } \\
\text { de Lisboa }\end{array}$} & UNL_CS & 3,82 & 4,32 & 4,50 & 4,05 & 3,91 & 3,82 & 3,82 & 4,14 & 3,82 & 3,82 \\
\hline & UNL_CM & 4,31 & 4,50 & 4,35 & 4,12 & 3,65 & 3,58 & 3,50 & 4,04 & 3,69 & 4,12 \\
\hline & UNL_CB & 4,15 & 4,64 & 4,51 & 3,77 & 4,21 & 3,79 & 3,87 & 4,41 & 3,62 & 4,08 \\
\hline & UNL_Eng & 4,06 & 4,28 & 4,31 & 3,98 & 3,97 & 3,67 & 3,87 & 4,28 & 3,83 & 4,05 \\
\hline & UNL_AL & 4,26 & 4,33 & 4,48 & 3,89 & 4,00 & 3,37 & 3,37 & 4,30 & 3,56 & 3,59 \\
\hline \multirow{5}{*}{$\begin{array}{l}\text { Universidade } \\
\text { Técnica de Lisboa }\end{array}$} & UTL_CS & 4,19 & 4,45 & 4,39 & 4,04 & 3,86 & 3,81 & 3,86 & 4,29 & 3,81 & 3,92 \\
\hline & UTL_CM & 4,20 & 4,90 & 4,50 & 4,00 & 3,90 & 3,30 & 3,30 & 3,90 & 3,40 & 3,90 \\
\hline & UTL_CB & 4,41 & 4,29 & 4,29 & 4,29 & 3,94 & 3,82 & 4,12 & 4,18 & 4,00 & 4,18 \\
\hline & UTL_Eng & 4,20 & 4,20 & 4,33 & 3,93 & 4,00 & 3,67 & 3,47 & 3,87 & 3,53 & 3,87 \\
\hline & UTL_AL & Excl. & -- & -- & -- & -- & -- & -- & -- & -- & -- \\
\hline \multirow{5}{*}{$\begin{array}{l}\text { Universidade de } \\
\text { Trás-os-Montes e } \\
\text { Alto Douro }\end{array}$} & UTAD_CS & 3,92 & 4,00 & 3,92 & 3,77 & 3,38 & 3,46 & 3,69 & 3,92 & 3,08 & 3,31 \\
\hline & UTAD_CM & Excl. & -- & -- & -- & -- & -- & -- & -- & -- & -- \\
\hline & UTAD_CB & Excl. & -- & -- & -- & -- & -- & -- & -- & -- & -- \\
\hline & UTAD_Eng & Excl. & -- & -- & -- & -- & -- & -- & -- & -- & -- \\
\hline & UTAD_AL & 4,09 & 4,73 & 3,55 & 4,27 & 3,91 & 3,64 & 4,27 & 3,82 & 3,64 & 3,91 \\
\hline
\end{tabular}

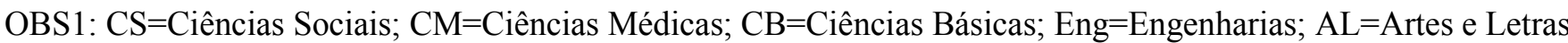

Fonte: Dados da pesquisa 
Com a redução das DMU's, a razão DMU's x inputs e outputs (como já demonstrado) alterou-se para 1,92. Esta razão ainda se encontra acima do que estabeleceu Avkiran (1999), validando os dados que constam na tabela 1 . Por fim, o software que apoiou as análises foi o Frontier Analyst.

\subsection{Análise geral de eficiência das DMU's}

Nesta análise, todos os inputs e outputs foram considerados em conjunto. Ou seja, buscou-se encontrar a eficiência das DMU's na visão de seus alunos, tomando por base a expectativa e a satisfação dos mesmos relacionado às três demandas, ao curso e à universidade. Esta é uma das funções do DEA: reunir atributos distintos em uma mesma análise. Os resultados estão apresentados na tabela 2 e na figura 2.

TABELA 2 Resultados da análise DEA com todos os inputs e outputs

$\begin{array}{cccccc}\text { DMU } & \text { Eficiência } & \text { DMU } & \text { Eficiência } & \text { DMU } & \text { Eficiência } \\ \text { UAc_AL } & 100,00 & \text { UC_Eng } & 97,28 & \text { Uminho_AL } & 65,53 \\ \text { UAc_CB } & 100,00 & \text { UEvora_AL } & 100,00 & \text { Uminho_CB } & 100,00 \\ \text { UAc_CM } & 100,00 & \text { UEvora_CB } & 100,00 & \text { Uminho_CM } & 98,45 \\ \text { UAc_CS } & 95,49 & \text { UEvora_CM } & 100,00 & \text { Uminho_CS } & 94,82 \\ \text { UAc_Eng } & 86,84 & \text { UEvora_CS } & 97,79 & \text { Uminho_Eng } & 95,91 \\ \text { UAlg_CM } & 90,56 & \text { UEvora_Eng } & 93,37 & \text { UNL_AL } & 95,97 \\ \text { UAlg_CS } & 100,00 & \text { UL_AL } & 91,07 & \text { UNL_CB } & 100,00 \\ \text { UAlg_Eng } & 100,00 & \text { UL_CB } & 95,91 & \text { UNL_CM } & 100,00 \\ \text { UBI_AL } & 100,00 & \text { UL_CM } & 92,75 & \text { UNL_CS } & 100,00 \\ \text { UBI_CB } & 100,00 & \text { UL_CS } & 99,28 & \text { UNL_Eng } & 98,39 \\ \text { UBI_CM } & 100,00 & \text { UL_Eng } & 100,00 & \text { UTAD_AL } & 100,00 \\ \text { UBI_CS } & 100,00 & \text { UMa_AL } & 100,00 & \text { UTAD_CS } & 100,00 \\ \text { UBI_Eng } & 93,43 & \text { UMa_CB } & 100,00 & \text { UTL_CB } & 100,00 \\ \text { UC_CB } & 99,43 & \text { UMa_CM } & 100,00 & \text { UTL_CM } & 93,97 \\ \text { UC_CM } & 97,27 & \text { UMa_CS } & 90,89 & \text { UTL_CS } & 98,16 \\ \text { UC_CS } & 91,55 & \text { UMa_Eng } & 100,00 & \text { UTL_Eng } & 94,51\end{array}$

Fonte: Dados da pesquisa

Analisando-se os dados apresentados na tabela 2 e na figura 2 a seguir, percebe-se que um número bastante razoável de DMU's apresentou eficiência. Foram 23 DMU's que, no conjunto dos inputs e outputs, apresentaram melhor eficiência relativa às demais DMU's. Isto significa que a relação expectativa versus satisfação nestas DMU's é melhor que nas demais DMU's analisadas. Porém, esta constatação oferece poucas pistas de melhores práticas, afinal foram quase metade das DMU's analisadas que demonstraram ser eficientes. 


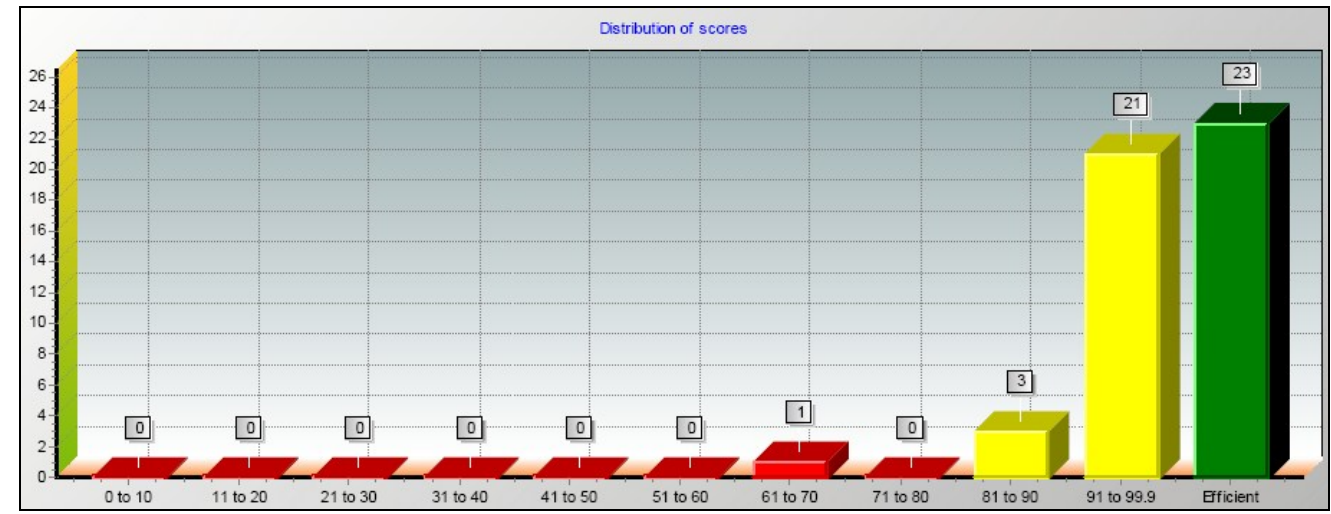

FIGURA 2 Resumo dos resultados da análise DEA com todos os inputs e outputs

Fonte: Dados da pesquisa

Para aumentar o poder de discriminação do DEA, o mesmo estabelece uma classificação de DMU's, baseada na comparação entre as DMU's eficientes e ineficientes. O objetivo desta comparação é mostrar a uma DMU ineficiente qual seria a DMU eficiente que serve como referência (benchmarking). Desta forma, as DMU's eficientes mais citadas como exemplos a serem seguidos são discriminadas como tendo a melhor relação relativa entre inputs e outputs. A figura 3 esclarece esta comparação.

Observando-se a figura 3, percebe-se que a DMU "UAlg_Eng" foi aquela que mais vezes foi considerada como o exemplo de DMU eficiente. Isto é, serve como referência para as DMU's ineficientes, e pode ser considerada como tendo a melhor relação entre as expectativas e satisfação, quando as demandas específicas, o curso e a universidade são analisados em conjunto. Próximo a esta DMU, surgiu a "UL_Eng”, como tendo a segunda melhor relação entre inputs e outputs, e assim sucessivamente para as demais DMU's eficientes.

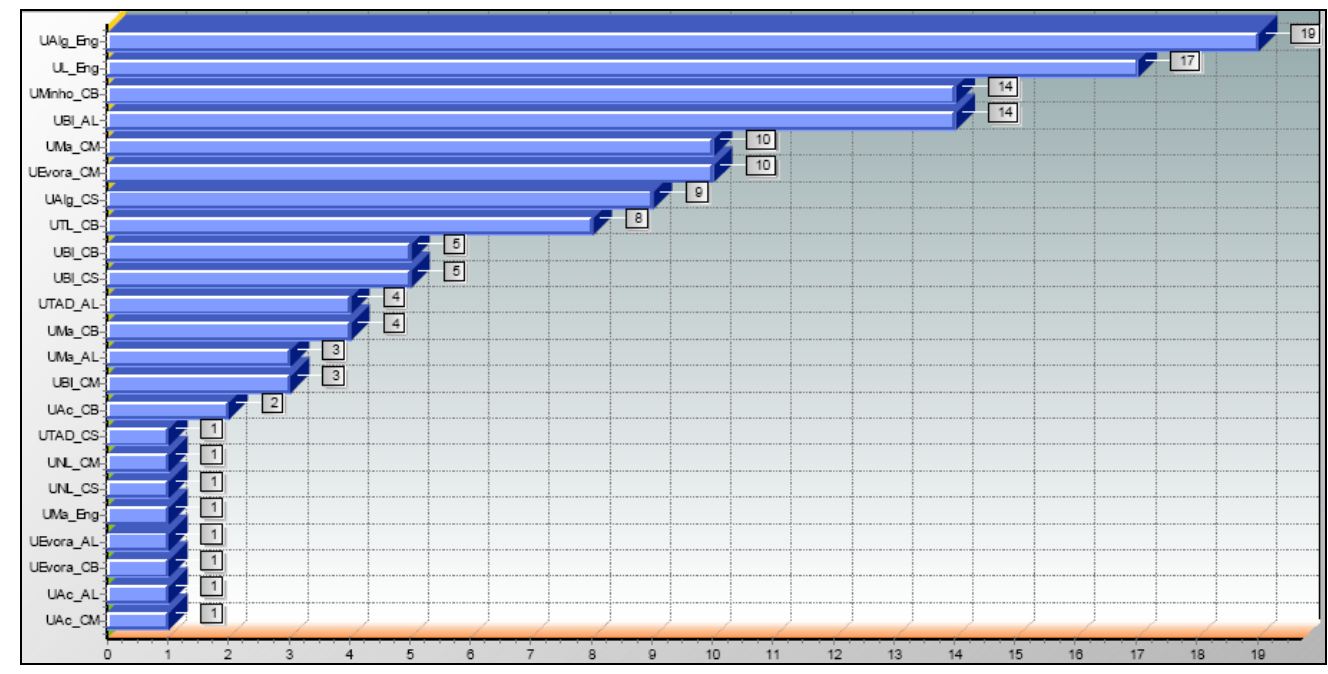

GRÁFICO 3 Classificação das DMU's eficientes

Fonte: Dados da pesquisa 
Retornando à tabela 2, também é preciso analisar as DMU's ineficientes. Das 25 DMU's ineficientes, 21 estão próximas à eficiência (acima de 91\%) e somente 4 DMU's apresentam uma eficiência considerada baixa. Destas, uma se destaca. É a DMU "UMinho_AL", com 65,53\% de eficiência. Uma observação nas notas médias desta DMU (vide tabela 1) é o suficiente para compreender o porquê desta eficiência tão baixa, ou seja, a satisfação dos alunos está muito aquém das expectativas e requer medidas para reverter tal situação, baseando-se principalmente em outras DMU's com alto desempenho. Outra situação foi a DMU "UAc_Eng". Esta DMU está um tanto distante da eficiência e requer ações direcionadas para aumentar sua eficiência, utilizando para isto uma comparação, por exemplo, com a DMU "UAlg_Eng", buscando compreender os motivos que levam aos alunos declararem que sua satisfação é inferior a suas expectativas (insatisfação).

Em resumo, os resultados obtidos mostraram um bom desempenho de grande parte das DMU's, afinal 23 delas estão na fronteira de eficiência relativa e outras 21 estão muito próximas desta fronteira. Isto pode significar que as Universidades Públicas Portuguesas têm atendido as expectativas dos alunos (com algumas exceções), deixando-os satisfeitos. Porém, com esta análise geral não é possível encontrar DMU's que se destaquem em um ou outro fator (outputs). Portanto, é preciso aprofundar as análises, buscando destacar desempenhos em situações específicas (as demandas). Estas análises ocorreram na sequência.

\subsection{Análise das principais demandas dos alunos}

Esta análise DEA envolveu especificamente as demandas que fizeram parte dos dados analisados de modo geral. A escolha destas demandas justifica-se pela importância que elas possuem na satisfação dos alunos com seu curso e com sua universidade (Mainardes, Alves e Domingues, 2009). Desta forma, cada demanda foi analisada da seguinte forma:

- Expectativas demanda e curso versus satisfação com a demanda (análise 1);

- Expectativas demanda e curso versus satisfação com o curso (análise 2);

- Expectativas demanda e universidade versus satisfação com a demanda (análise 3);

- Expectativas demanda e universidade versus satisfação com a universidade (análise 4);

- Expectativas demanda versus satisfação com a demanda (análise 5).

Considerando que são três as demandas, cada uma foi analisada separadamente. Um resumo dos resultados das análises DEA para a demanda "grau de exigência do curso" é apresentado na tabela 3 . 
TABELA 3 Resumos dos resultados das análises DEA para demanda "Grau de Exigência do Curso"

\begin{tabular}{|c|c|c|c|c|c|}
\hline & Análise 1 & Análise 2 & Análise 3 & Análise 4 & $\begin{array}{c}\text { Análise } \\
5\end{array}$ \\
\hline Inputs & MEE e MEC & $\begin{array}{c}\text { MEE e } \\
\text { MEC }\end{array}$ & MEE e MEU & MEE e MEU & MEE \\
\hline Outputs & MSE & MSC & MSE & MSU & MSE \\
\hline \multicolumn{6}{|l|}{ DMU } \\
\hline UAc_AL & 90,72 & 85,26 & 83,56 & 91,34 & 82,80 \\
\hline $\mathrm{UAc} \mathrm{CB}$ & 82,35 & 88,36 & 82,46 & 78,48 & 78,83 \\
\hline UAc_CM & 100,00 & 100,00 & 100,00 & 100,00 & 94,50 \\
\hline UAc_CS & 87,65 & 91,45 & 82,85 & 94,54 & 81,67 \\
\hline UAc_Eng & 79,76 & 86,10 & 80,37 & 80,20 & 75,04 \\
\hline UAlg_CM & 82,65 & 88,45 & 81,60 & 86,95 & 79,49 \\
\hline UAlg_CS & 89,88 & 97,71 & 89,88 & 98,81 & 87,13 \\
\hline UAlg_Eng & 86,35 & 93,96 & 86,35 & 100,00 & 82,66 \\
\hline UBI_AL & 100,00 & 100,00 & 95,69 & 100,00 & 90,09 \\
\hline UBI_CB & 97,80 & 93,09 & 94,74 & 92,33 & 83,22 \\
\hline UBI_CM & 92,71 & 95,79 & 100,00 & 100,00 & 83,52 \\
\hline UBI_CS & 90,35 & 99,24 & 90,78 & 96,80 & 86,49 \\
\hline UBI_Eng & 80,00 & 84,13 & 80,74 & 79,75 & 76,58 \\
\hline $\mathrm{UC} \_\mathrm{CB}$ & 90,35 & 92,01 & 90,35 & 98,39 & 81,59 \\
\hline $\mathrm{UC} \mathrm{CM}$ & 88,24 & 81,55 & 88,24 & 85,65 & 75,08 \\
\hline $\mathrm{UC} C \mathrm{CS}$ & 80,94 & 75,34 & 80,94 & 79,43 & 69,80 \\
\hline UC Eng & 87,76 & 93,36 & 87,76 & 96,45 & 81,17 \\
\hline UEvora_AL & 81,18 & 98,46 & 81,41 & 84,70 & 75,99 \\
\hline UEvora_CB & 91,52 & 93,00 & 87,06 & 86,91 & 80,45 \\
\hline UEvora_CM & 89,41 & 100,00 & 89,76 & 92,67 & 74,42 \\
\hline UEvora_CS & 87,29 & 91,00 & 85,65 & 82,78 & 79,79 \\
\hline UEvora_Eng & 87,76 & 85,25 & 87,76 & 78,37 & 81,56 \\
\hline UL_AL & 83,53 & 79,90 & 83,53 & 80,64 & 74,03 \\
\hline $\mathrm{UL}$ CB & 86,82 & 92,11 & 86,82 & 90,27 & 75,90 \\
\hline $\mathrm{UL} C \mathrm{CM}$ & 85,65 & 82,39 & 86,37 & 83,58 & 77,89 \\
\hline $\mathrm{UL}_{-} \mathrm{CS}$ & 89,65 & 93,03 & 89,65 & 90,64 & 81,34 \\
\hline UL_Eng & 100,00 & 100,00 & 88,24 & 96,85 & 84,46 \\
\hline UMa_AL & 90,12 & 92,31 & 90,31 & 92,22 & 86,26 \\
\hline UMa_CB & 90,82 & 91,79 & 91,76 & 100,00 & 88,49 \\
\hline UMa_CM & 100,00 & 100,00 & 100,00 & 100,00 & 100,00 \\
\hline UMa_CS & 83,76 & 84,08 & 83,96 & 85,74 & 79,39 \\
\hline UMa_Eng & 100,00 & 100,00 & 100,00 & 100,00 & 78,59 \\
\hline UMinho_AL & 54,12 & 43,90 & 54,12 & 38,28 & 43,17 \\
\hline UMinho_CB & 100,00 & 91,09 & 100,00 & 100,00 & 97,67 \\
\hline UMinho_CM & 87,76 & 95,78 & 87,76 & 93,68 & 75,51 \\
\hline UMinho_CS & 87,06 & 91,72 & 87,06 & 90,30 & 76,45 \\
\hline UMinho_Eng & 89,88 & 81,96 & 89,88 & 86,27 & 86,04 \\
\hline UNL $\bar{A} L$ & 79,29 & 87,63 & 79,29 & 86,26 & 71,27 \\
\hline UNL_CB & 89,18 & 89,54 & 89,18 & 98,35 & 82,28 \\
\hline UNL_CM & 84,24 & 90,05 & 84,46 & 100,00 & 74,83 \\
\hline UNL_CS & 91,56 & 94,08 & 90,77 & 100,00 & 90,09 \\
\hline UNL_Eng & 86,35 & 94,05 & 86,35 & 97,89 & 81,44 \\
\hline UTAD AL & 85,65 & 88,78 & 85,65 & 94,42 & 80,18 \\
\hline UTAD CS & 81,41 & 76,31 & 82,21 & 84,53 & 79,52 \\
\hline
\end{tabular}




\begin{tabular}{|c|c|c|c|c|c|}
\hline UTL_CB & 89,88 & 97,56 & 89,88 & 100,00 & 78,04 \\
\hline UTL_CM & 77,65 & 83,38 & 77,65 & 93,89 & 70,79 \\
\hline UTL_CS & 89,65 & 93,30 & 89,65 & 94,55 & 81,92 \\
\hline UTL_Eng & 86,35 & 86,79 & 86,35 & 93,15 & 78,72 \\
\hline Total DMU's eficientes & 6 & 6 & 5 & 11 & NT \\
\hline $\begin{array}{c}\text { Total DMU's ineficientes } \\
\text { 91\% a 99\% }\end{array}$ & 4 & 21 & 3 & 17 & NT \\
\hline $\begin{array}{c}\text { Total DMU's ineficientes } \\
\text { 81\% a 90\% }\end{array}$ & 32 & 17 & 34 & 13 & NT \\
\hline $\begin{array}{c}\text { Total DMU's ineficientes } \\
\text { 80\% ou menos }\end{array}$ & 6 & 4 & 6 & 7 & NT \\
\hline DMU's de fronteira & $\begin{array}{c}\text { UMa_CM e } \\
\text { UMinho_CB }\end{array}$ & $\begin{array}{c}\text { UMa_CM e } \\
\text { UL_Eng }\end{array}$ & UMa_CM & $\begin{array}{c}\text { UMinho_CB, } \\
\text { UMa_CB e } \\
\text { UBI_CM }\end{array}$ & NT \\
\hline
\end{tabular}

Fonte: Dados da pesquisa

Tendo em mente que o grau de exigência do curso é um dos principais atributos que formam as percepções dos alunos com relação ao seu curso e à sua universidade (Mainardes, Alves e Domingues, 2009), esta análise buscou identificar as DMU's que mais conseguem atender as expectativas de seus alunos, quando comparado com outras DMU's (faculdades). Isto não significa a eficiência absoluta, mas sim, a eficiência relativa quando diversas faculdades (DMU's) são testadas em conjunto.

Analisando os dados da tabela 3, inicialmente percebe-se que, das 48 DMU's, entre 5 e 11 foram eficientes quando se testou o grau de exigência do curso. Portanto, vê-se que esta demanda requer melhorias em grande parte das DMU's testadas, ou seja, os alunos, de modo geral, nutrem expectativas sobre o grau de exigência do curso que freqüentam, e estas expectativas não estão sendo alcançadas de modo equivalente (satisfação). Com relação ao curso e à universidade, destaque para a DMU "UMa_CM", onde os alunos demonstraram que suas expectativas quanto ao grau de exigência do curso foram superadas e eles mostram mais satisfação do que em outras DMU's. Esta DMU em especial demonstrou uma melhor eficiência em todos os testes realizados, sempre fazendo parte das fronteiras de eficiência. Outras DMU's se destacaram também: "UAc_CM", "UBI_AL", “UBI_CM", "UL_Eng" e “UMinho_CB". Estas DMU's apresentaram eficiência relativa superior às demais DMU's. Constatou-se também que grande parte das DMU's está com mais de $81 \%$ de eficiência, portanto as ações que venham a ajustar a satisfação dos alunos com as suas expectativas não requerem tantos esforços para alcançar a fronteira de eficiência.

A segunda demanda foi a "realização pessoal". Realizou-se os mesmos testes feitos com a demanda anterior. Os resultados são apresentados na tabela 4. 
TABELA 4 Resumos dos resultados das análises DEA para demanda-chave "Realização Pessoal"

\begin{tabular}{|c|c|c|c|c|c|}
\hline & Análise 1 & Análise 2 & Análise 3 & Análise 4 & Análise 5 \\
\hline Inputs & $\begin{array}{c}\text { MER e } \\
\text { MEC }\end{array}$ & MER e MEC & MER e MEU & MER e MEU & MER \\
\hline Outputs & MSR & MSC & MSR & $\mathrm{MSU}$ & MSR \\
\hline \multicolumn{6}{|l|}{ DMU } \\
\hline UAc_AL & 90,92 & 86,18 & 86,70 & 89,75 & 81,33 \\
\hline UAc_CB & 96,77 & 88,17 & 95,90 & 77,48 & 77,20 \\
\hline UAc_CM & 93,79 & 97,56 & 93,79 & 81,58 & 81,03 \\
\hline UAc_CS & 92,12 & 89,73 & 89,97 & 90,49 & 75,56 \\
\hline UAc_Eng & 84,06 & 86,77 & 84,06 & 81,84 & 72,88 \\
\hline UAlg_CM & 84,84 & 88,82 & 83,20 & 87,25 & 73,04 \\
\hline UAlg CS & 96,46 & 99,31 & 96,46 & 97,69 & 84,68 \\
\hline UAlg_Eng & 94,15 & 95,31 & 93,61 & 100,00 & 82,92 \\
\hline UBI_AL & 100,00 & 100,00 & 100,00 & 100,00 & 93,81 \\
\hline UBI_CB & 99,81 & 93,44 & 96,06 & 95,02 & 83,29 \\
\hline UBI_CM & 95,70 & 95,76 & 100,00 & 100,00 & 72,49 \\
\hline UBI_CS & 97,85 & 99,19 & 97,01 & 96,11 & 81,15 \\
\hline UBI_Eng & 83,34 & 85,09 & 83,70 & 81,67 & 72,90 \\
\hline $\mathrm{UC} \mathrm{CB}$ & 90,08 & 92,00 & 86,38 & 98,09 & 70,19 \\
\hline $\mathrm{UC} \mathrm{CM}$ & 82,61 & 81,55 & 81,63 & 85,65 & 65,21 \\
\hline $\mathrm{UC} C \mathrm{CS}$ & 89,61 & 76,49 & 89,61 & 79,96 & 78,38 \\
\hline UC Eng & 87,02 & 93,44 & 87,02 & 95,69 & 73,28 \\
\hline UEvora AL & 95,69 & 98,54 & 95,44 & 84,81 & 81,19 \\
\hline UEvora_CB & 94,30 & 93,00 & 89,50 & 87,61 & 74,54 \\
\hline UEvora_CM & 100,00 & 100,00 & 100,00 & 92,67 & 79,28 \\
\hline UEvora_CS & 97,79 & 90,95 & 93,88 & 82,31 & 78,40 \\
\hline UEvora_Eng & 87,72 & 85,31 & 86,99 & 78,03 & 73,75 \\
\hline $\mathrm{UL} \overline{\mathrm{AL}}$ & 85,20 & 79,88 & 84,68 & 80,54 & 68,70 \\
\hline $\mathrm{UL}$ CB & 94,44 & 92,21 & 94,44 & 90,19 & 77,97 \\
\hline UL_CM & 84,96 & 84,34 & 84,96 & 87,39 & 76,10 \\
\hline UL CS & 96,54 & 93,77 & 96,54 & 90,67 & 83,71 \\
\hline UL_Eng & 100,00 & 100,00 & 91,98 & 96,00 & 79,75 \\
\hline UMa_AL & 100,00 & 100,00 & 100,00 & 100,00 & 100,00 \\
\hline UMa_CB & 97,46 & 91,64 & 96,62 & 98,54 & 76,29 \\
\hline UMa_CM & 97,60 & 100,00 & 100,00 & 93,40 & 82,46 \\
\hline UMa_CS & 88,93 & 83,99 & 86,12 & 84,67 & 70,99 \\
\hline UMa_Eng & 100,00 & 100,00 & 81,15 & 83,94 & 69,95 \\
\hline UMinho_AL & 47,33 & 43,90 & 47,33 & 38,28 & 39,33 \\
\hline UMinho_CB & 93,65 & 90,80 & 90,40 & 98,53 & 75,12 \\
\hline UMinho_CM & 95,44 & 96,03 & 95,44 & 93,68 & 81,19 \\
\hline UMinho_CS & 89,58 & 92,01 & 89,58 & 90,46 & 76,47 \\
\hline UMinho_Eng & 82,76 & 82,67 & 82,76 & 85,81 & 71,50 \\
\hline UNL_AL & 80,87 & 87,80 & 80,55 & 85,89 & 68,88 \\
\hline UNL_CB & 94,58 & 89,49 & 90,84 & 97,61 & 73,81 \\
\hline UNL_CM & 82,83 & 90,16 & 82,83 & 100,00 & 68,83 \\
\hline UNL_CS & 91,36 & 93,99 & 91,36 & 91,52 & 78,25 \\
\hline UNL Eng & 92,78 & 94,65 & 92,78 & 96,96 & 80,02 \\
\hline UTAD_AL & 99,70 & 88,78 & 99,70 & 93,68 & 79,89 \\
\hline UTAD_CS & 90,19 & 78,07 & 89,95 & 88,69 & 81,64 \\
\hline UTL_CB & 98,71 & 98,42 & 98,71 & 100,00 & 84,99 \\
\hline
\end{tabular}




\begin{tabular}{|c|c|c|c|c|c|}
\hline UTL_CM & 77,89 & 83,27 & 76,74 & 93,49 & 59,60 \\
\hline UTL_CS & 91,61 & 93,38 & 91,61 & 94,15 & 76,76 \\
\hline UTL_Eng & 83,58 & 87,85 & 83,58 & 93,21 & 73,11 \\
\hline $\begin{array}{c}\text { Total DMU's } \\
\text { eficientes }\end{array}$ & 5 & 6 & 5 & 6 & NT \\
\hline $\begin{array}{c}\text { Total DMU's } \\
\text { ineficientes 91\% } \\
\text { a 99\% }\end{array}$ & 23 & 19 & 18 & 18 & NT \\
\hline $\begin{array}{c}\text { Total DMU's } \\
\text { ineficientes 81\% } \\
\text { a 90\% }\end{array}$ & 17 & 19 & 22 & 19 & NT \\
\hline $\begin{array}{c}\text { Total DMU's } \\
\text { ineficientes 80\% } \\
\text { ou menos }\end{array}$ & 3 & 4 & 3 & 5 & NT \\
\hline $\begin{array}{c}\text { DMU's de } \\
\text { fronteira }\end{array}$ & $\begin{array}{c}\text { UMa_AL, } \\
\text { UBI_AL_Eng }\end{array}$ & $\begin{array}{c}\text { UMa_AL e } \\
\text { UL_Eng }\end{array}$ & $\begin{array}{c}\text { UMa_AL, } \\
\text { UBI_AL_C }\end{array}$ & $\begin{array}{c}\text { UMa_AL e } \\
\text { UBI_CM }\end{array}$ & NT \\
\hline
\end{tabular}

Fonte: Dados da pesquisa

Considerando que a demanda realização pessoal influencia diretamente a satisfação dos alunos (Mainardes, Alves e Domingues, 2009), tanto com seu curso, quanto com sua universidade, as análises desta demanda revelaram que a DMU mais eficiente em todos os testes foi a "UMa_AL". Esta DMU demonstrou eficiência relativa, quando comparada com as demais, sempre estando presente nas fronteiras de eficiência. Sendo assim, esta DMU pode servir de exemplo para as demais DMU's, especialmente aquelas que estão próximas à fronteira de eficiência ( $81 \%$ ou mais de eficiência relativa), afinal, a realização pessoal dos alunos influencia diretamente sua percepção com relação ao seu curso e à sua universidade, afetando assim sua satisfação. Outras DMU's de destaque foram: "UBI_AL", "UEvora_CM", "UL_Eng" e "UMa_CM". Estas demonstram bons resultados, quando comparados com as demais faculdades.

Como no caso anterior, foram poucas as DMU's bastante ineficientes $(80 \%$ ou menos), sendo que estas requerem mais atenção dos gestores universitários onde os alunos geram expectativas sobre a sua realização pessoal e isto não se confirma (causando insatisfação), podendo desmotivar os alunos, assim como pode aumentar o número de desistências. Em suma, estas DMU's devem receber atenção prioritária. Quanto às demais DMU's, algumas ações localizadas podem se refletir na percepção de satisfação dos alunos.

A última demanda testada foi o "ambiente da universidade". Como realizado com as demandas anteriores, foram efetuadas as cinco análises e os resultados estão apresentados na tabela 5 . 
TABELA 5 Resumos dos resultados das análises DEA para demanda-chave "Ambiente da Universidade"

\begin{tabular}{|c|c|c|c|c|c|}
\hline & Análise 1 & Análise 2 & Análise 3 & Análise 4 & Análise 5 \\
\hline Inputs & MEA e MEC & MEA e MEC & MEA e MEU & MEA e MEU & MEA \\
\hline Outputs & MSA & MSC & MSA & MSU & MSA \\
\hline \multicolumn{6}{|l|}{ DMU } \\
\hline UAc_AL & 84,70 & 83,35 & 88,07 & 85,34 & 77,57 \\
\hline UAc CB & 100,00 & 89,72 & 100,00 & 83,70 & 100,00 \\
\hline UAc_CM & 91,77 & 96,85 & 94,66 & 80,37 & 84,51 \\
\hline UAc_CS & 89,41 & 89,99 & 94,08 & 91,09 & 81,88 \\
\hline UAc_Eng & 79,61 & 86,07 & 83,46 & 79,78 & 71,47 \\
\hline UAlg_CM & 85,71 & 88,27 & 88,79 & 85,59 & 78,93 \\
\hline UAlg CS & 98,39 & 97,96 & 98,39 & 97,21 & 92,86 \\
\hline UAlg Eng & 100,00 & 94,77 & 100,00 & 100,00 & 97,39 \\
\hline UBI AL & 99,46 & 98,74 & 100,00 & 100,00 & 91,41 \\
\hline UBI_CB & 98,35 & 100,00 & 95,92 & 97,38 & 88,15 \\
\hline UBI CM & 93,11 & 95,76 & 100,00 & 100,00 & 78,48 \\
\hline UBI_CS & 93,96 & 99,73 & 96,96 & 98,39 & 89,02 \\
\hline UBI_Eng & 88,62 & 84,16 & 93,40 & 80,62 & 80,71 \\
\hline $\mathrm{UC} \mathrm{CB}$ & 93,58 & 92,09 & 94,26 & 98,09 & 83,71 \\
\hline $\mathrm{UC} \mathrm{CM}$ & 95,82 & 82,01 & 95,82 & 85,83 & 90,09 \\
\hline $\mathrm{UC} \mathrm{CS}$ & 88,58 & 75,80 & 88,58 & 79,82 & 84,08 \\
\hline UC Eng & 94,20 & 93,48 & 94,20 & 95,69 & 86,59 \\
\hline UEvora_AL & 100,00 & 100,00 & 100,00 & 100,00 & 92,26 \\
\hline UEvora_CB & 95,25 & 93,24 & 99,98 & 87,62 & 86,44 \\
\hline UEvora_CM & 95,56 & 100,00 & 98,75 & 92,67 & 84,21 \\
\hline UEvora_CS & 89,05 & 91,43 & 89,70 & 82,32 & 82,77 \\
\hline UEvora_Eng & 88,46 & 85,70 & 89,48 & 78,20 & 83,49 \\
\hline UL_AL & 88,84 & 80,03 & 89,40 & 80,54 & 80,92 \\
\hline UL_CB & 79,08 & 92,20 & 79,08 & 90,19 & 71,51 \\
\hline $\mathrm{UL} \mathrm{CM}$ & 85,87 & 82,94 & 89,85 & 90,16 & 82,47 \\
\hline UL_CS & 93,64 & 93,86 & 93,73 & 91,18 & 91,20 \\
\hline UL_Eng & 100,00 & 100,00 & 100,00 & 95,79 & 88,52 \\
\hline UMa AL & 84,85 & 92,84 & 86,65 & 92,91 & 81,02 \\
\hline UMa_CB & 93,88 & 91,75 & 99,50 & 100,00 & 84,28 \\
\hline UMa_CM & 92,24 & 100,00 & 98,11 & 97,96 & 85,90 \\
\hline UMa_CS & 86,57 & 84,19 & 88,73 & 84,67 & 78,70 \\
\hline UMa_Eng & 100,00 & 100,00 & 81,89 & 83,43 & 70,43 \\
\hline UMinho_AL & 65,53 & 44,09 & 65,53 & 38,47 & 62,21 \\
\hline UMinho_CB & 96,22 & 90,80 & 97,79 & 98,53 & 83,53 \\
\hline UMinho_CM & 95,81 & 96,08 & 95,81 & 93,68 & 88,23 \\
\hline UMinho_CS & 92,38 & 91,87 & 93,25 & 90,29 & 83,99 \\
\hline UMinho_Eng & 90,47 & 82,30 & 91,01 & 85,86 & 86,21 \\
\hline UNL_AL & 95,97 & 87,71 & 95,97 & 85,89 & 86,47 \\
\hline UNL_CB & 98,30 & 89,59 & 98,30 & 97,61 & 88,09 \\
\hline UNL_CM & 90,69 & 90,23 & 92,94 & 100,00 & 83,67 \\
\hline UNL_CS & 92,32 & 93,48 & 92,34 & 91,52 & 82,88 \\
\hline UNL_Eng & 96,24 & 94,29 & 96,24 & 96,89 & 89,46 \\
\hline UTAD_AL & 100,00 & 100,00 & 100,00 & 100,00 & 96,94 \\
\hline UTAD_CS & 100,00 & 100,00 & 100,00 & 100,00 & 90,09 \\
\hline UTL $\overline{C B}$ & 94,08 & 97,60 & 94,08 & 100,00 & 87,78 \\
\hline
\end{tabular}




\begin{tabular}{|c|c|c|c|c|c|}
\hline UTL_CM & 86,97 & 83,37 & 87,07 & 93,49 & 78,08 \\
\hline UTL_CS & 96,13 & 93,42 & 96,52 & 94,15 & 88,04 \\
\hline UTL_Eng & 86,95 & 87,06 & 86,95 & 92,58 & 80,52 \\
\hline $\begin{array}{c}\text { Total DMU's } \\
\text { eficientes }\end{array}$ & 7 & 8 & 8 & 9 & $\mathrm{NT}$ \\
\hline $\begin{array}{c}\text { Total DMU's } \\
\text { ineficientes } \\
\text { 91\% a 99\% }\end{array}$ & 23 & 20 & 25 & 19 & $\mathrm{NT}$ \\
\hline $\begin{array}{c}\text { Total DMU's } \\
\text { ineficientes } \\
\text { 81\% a 90\% }\end{array}$ & 15 & 17 & 13 & 13 & $\mathrm{NT}$ \\
\hline $\begin{array}{c}\text { Total DMU's } \\
\text { ineficientes } \\
\text { 80\% ou menos }\end{array}$ & 3 & 3 & 2 & 7 & $\mathrm{NT}$ \\
\hline $\begin{array}{c}\text { DMU's de } \\
\text { fronteira }\end{array}$ & $\begin{array}{c}\text { UAlg_Eng e } \\
\text { UL_Eng }\end{array}$ & $\begin{array}{c}\text { UEvora_AL e } \\
\text { UL_Eng }\end{array}$ & $\begin{array}{c}\text { UAc_CB, } \\
\text { UBI_AL e } \\
\text { UBI_CM }\end{array}$ & $\begin{array}{c}\text { UTAD_AL, } \\
\text { UAL_Eng, } \\
\text { UnI_CM e }\end{array}$ & NT \\
\hline
\end{tabular}

Fonte: Dados da pesquisa

Quando se analisou a demanda referente ao ambiente da universidade (tabela 5), percebeu-se que os resultados foram mais elevados. Constatou-se que esta demanda é aquela que mais alunos estão satisfeitos, quando comparado com as expectativas dos mesmos. Em especial, pode-se citar a relação entre expectativa e satisfação dos alunos das DMU's “UAc_CB" e "UEvora_AL". Estas duas DMU's apresentaram os melhores resultados em termos de eficiência relativa, apesar de nenhuma das duas (nem as demais 46 DMU's) terem tido $100 \%$ de eficiência em todos os testes. Isto é, o ambiente nestas DMU's parece atender melhor as expectativas dos alunos, quando comparado com as demais DMU's. Outras DMU's bem posicionadas foram: "UAlg_Eng", “UBI_AL", “UBI_CB”, UBI_CM", “UL_Eng”, “UTAD_AL" e "UTAD_CS". Qualquer uma delas pode servir de referência para as demais DMU's.

Considerando que o ambiente de universidade é um fator importante na atração, retenção e relacionamento com os alunos, as DMU's com eficiência de $80 \%$ ou menos requerem uma atenção específica dos gestores destas DMU's. E isto pode ser feito ao estudar os processos e a forma de agir das DMU's consideradas eficientes, afinal desenvolver um bom ambiente na universidade mostra-se importante para a aprendizagem dos alunos, bem como para sua permanência no curso e na universidade (MAINARDES; ALVES; DOMINGUES, 2009).

Por fim, outro ponto a destacar é que aquelas DMU's que tiveram bom desempenho nas análises das demandas específicas e não tiveram desempenho equivalente na análise geral, 
devem analisar seu desempenho referente à outras demandas, pois se as três demandas testadas parecem estar sendo atendidas (satisfação), possivelmente as fontes de insatisfação, que impactam na satisfação geral, provém de outras demandas e precisam ser investigados os motivos da insatisfação dos seus alunos.

\section{CONCLUSÕES E RECOMENDAÇÕES}

Ao finalizar esta etapa, cujo objetivo foi avaliar o desempenho das Universidades Públicas Portuguesas, tomando por base as expectativas e satisfação de seus alunos e utilizando o método DEA, obteve-se, como resultado, as faculdades que demonstram uma boa relação entre a expectativa e satisfação dos alunos, o que pode, a partir de práticas gerenciais exitosas, auxiliar a melhoria da eficiência das faculdades tidas como ineficientes. Como comentado inicialmente, a literatura de gestão de universidades raramente demonstra o desempenho da universidade baseado nas percepções de seus alunos, sendo esta a principal contribuição desta investigação.

A partir de análises comparativas entre as várias faculdades que pertencem às 11 universidades investigadas, obteve-se a eficiência relativa destas faculdades, chamadas de DMU's, na visão de seus alunos. A análise considerando faculdades (e não as universidades como um todo) deve-se ao fato de as universidades serem um conjunto de faculdades, e muitos dos processos e técnicas de gestão variam entre faculdades da mesma universidade (Weick, 1976).

Portanto, considerando os resultados obtidos, constatou-se que o porte da universidade não garante a eficiência. Ou seja, independente do tamanho, a eficiência no atendimento das expectativas dos alunos pode ser alcançada e o porte da universidade não pode ser justificativa para a ineficiência relativa da organização. Além disso, para as DMU's consideradas mais eficientes em grande parte dos aspectos, isto não significa exatamente que devem manter o trabalho desenvolvido, mas deve ser um estímulo ao desenvolvimento constante de melhorias, voltadas à ampliação da satisfação de seus alunos, especialmente aprofundando o relacionamento com os mesmos para compreender melhor suas expectativas e realizar ações com vistas a atender e superar tais expectativas (Arnett, German e Hunt, 2003).

Já para as DMU's ineficientes, uma avaliação aprofundada de sua realidade, bem como a análise comparada com DMU's eficientes, que podem ser referências para a melhoria da eficiência (Shaw, 2009), serve para compreender o que falta para atingir e superar as expectativas de seus alunos. Estas ações não necessariamente exigem elevados recursos, pois 
medidas simples podem ser a diferença entre estar ou não na fronteira de eficiência. $\mathrm{O}$ foco deve ser a satisfação dos alunos (Jongbloed, Enders e Salerno, 2008).

Outra constatação deste estudo é que somente atender as expectativas relacionadas à determinadas demandas não são suficientes para garantir a satisfação dos alunos. As análises realizadas mostraram que algumas DMU's são eficientes quanto às expectativas dos alunos com relação à determinadas demandas, mas não são eficientes na análise da visão geral dos alunos. Portanto, a replicação da análise com outras demandas podem indicar as fontes de insatisfação dos alunos, que impedem que uma DMU chegue à fronteira de eficiência na análise geral.

Além disso, constatou-se também que uma universidade pode ter faculdades eficientes (fronteira de eficiência) e outras ineficientes (distantes da fronteira de eficiência). Como Weick (1976) defende, a universidade é um sistema de unidades frouxamente acopladas, o que leva a distorções deste gênero. Para estes casos, sem dúvida, constata-se que a universidade não é uma organização única, que trabalha de modo uniforme, mas sim um conjunto de unidades independentes, com desempenhos distintos. Portanto, ao invés de unir forças e crescer conjuntamente, determinadas universidades não seguem uma estratégia única, desperdiçando uma de suas principais forças, a capacidade de ser multidisciplinar perseguindo um objetivo único (Galbraith, 2003).

Quanto às análises de demandas específicas, algumas constatações surgiram. Uma delas é que boa parte dos alunos considera que esperavam cursos mais exigentes, afinal poucas DMU's atingiram a eficiência, sendo que as universidades menores tiveram um melhor desempenho. Mas não foi porque são exigentes, mas sim porque as expectativas dos alunos eram menores. Por outro lado, grande parte das faculdades não está distante de alcançarem as expectativas dos alunos, chegando assim à fronteira de eficiência. Da mesma forma, esta mesma constatação pode ser considerada para a demanda ligada à realização pessoal.

Por fim, quanto ao ambiente das universidades, mais DMU's mostraram-se eficientes. Mais uma vez, o ambiente das universidades menores foi melhor percebido pelos alunos, o que pode ser explicado justamente por ser um ambiente menor, com uma maior sensação de pertença do aluno a um ambiente menos plural. Além disso, observaram-se universidades onde o ambiente de uma faculdade é considerado bastante eficiente e de outra faculdade, bastante ineficiente. Isto pode estar relacionado ao curso, que pode afetar a percepção dos alunos quanto ao ambiente da universidade. 
Como principal recomendação após a realização desta etapa da investigação, reforçase a utilização de análises de eficiência utilizando o DEA na medição do desempenho da universidade na visão de seus alunos. Segundo Zhu (2009), este tipo de análise pode ser útil para as universidades para:

- $\quad$ Alocação de recursos dentro da universidade (busca da eficiência por unidades ineficientes);

- Identificação das melhores práticas;

- Definição de metas a serem alcançadas por cada unidade;

- Monitoramento das mudanças de eficiência no decorrer do tempo;

- Identificação de unidades a serem recompensadas por bom desempenho;

- Planejamento de posicionamento e investimentos.

Portanto, este tipo de análise demonstra ser uma ferramenta gerencial útil para o alcance dos objetivos de uma universidade. Desta forma, a realização deste tipo de análise, considerando expectativa e satisfação como inputs e outputs, pode ser desenvolvida, identificando, por exemplo, faculdades e/ou universidades que são eficientes na missão ensino e ineficientes na missão investigação.

Como limitações ao estudo realizado, basicamente estão relacionadas ao método utilizado, especialmente no que se refere à não medição da eficiência absoluta. Isto é, uma DMU pode ter eficiência relativa (melhor desempenho comparado com outras DMU's), mas seu desempenho não alcançar os objetivos propostos (eficácia). O método DEA não permite isto, sendo uma limitação a ser considerada nas análises. Portanto, outros métodos podem acompanhar as análises, para que seja possível concluir que o desempenho de uma unidade está dentro ou acima do esperado. Outra limitação é o número de DMU's que o método exige.

Para comparações entre poucas unidades (como seria o caso de uma análise entre as 11 universidades), o método não discrimina bem as diferenças entre as DMU's, exigindo assim um número relativamente elevado de unidades a analisar. Desta forma, uma ampliação do universo de pesquisa pode contribuir para posicionar em termos de eficiência as Universidades Públicas Portuguesas no contexto do ensino superior português. Apesar das limitações, o método apresentado mostrou-se útil para demonstrar as percepções dos alunos quanto aos cursos e às próprias Universidades Públicas Portuguesas e suas faculdades. 


\section{AGRADECIMENTOS}

Esta pesquisa foi financiada pela FCT através do NECE - Núcleo de Investigação em Ciências Empresariais (Programa de Financiamento Plurianual das Unidades de I\&D da FCT - Fundação para a Ciência e Tecnologia, Ministério da Ciência, Tecnologia e Ensino Superior/ Portugal).

\section{REFERÊNCIAS}

ALVES, H.; RAPOSO, M.. Student Satisfaction Index in Portuguese public higher education, The Service Industries Journal, vol. 27, nº 6, pp. 795-808, 2007.

ANDERSON, E.; FORNELL, C. The Customer Satisfaction Index as a leading indicator. In: Swartz, T. e Iacobucci, D. (Eds.), Handbook of service marketing and management. London: Sage Publications, pp. 255-267, 2000.

ARNETT, D.; GERMAN, S.; HUNT, S. The identity salience model of relationship marketing success: the case of nonprofit marketing, Journal of Marketing, vol. 67, $\mathrm{n}^{\circ}$ 1, pp. 89-105, 2003.

AVKIRAN, N. An application reference for data envelopment analysis in branch banking: helping the novice researcher, International Journal of Bank Marketing, vol. 17, $\mathrm{n}^{\mathrm{o}}$ 5, pp. 206-220, 1999.

AVKIRAN, N. Investigating technical and scale efficiencies of Australian universities through data envelopment analysis, Socio-Economic Planning Sciences, vol. 35, $\mathrm{n}^{\circ}$ 1, pp. $57-$ $80,2001$.

BANKER, R.. MAINDIRATTA, A. Piecewise loglinear estimation of efficient production surfaces, Management Science, vol. 32, n 1, pp. 126-135, 1986.

BANKER, R.; MOREY, R. Efficiency analysis for exogenously fixed inputs and outputs, Operations Research, vol. 34, n 4, pp. 513-521, 1986.

BANKER, R.; CHARNES, A.; COOPER, W. Some models for estimating technical and scale inefficiencies in data envelopment analysis, Management Science, vol. 30, n 9, pp. 10781092, 1984.

CHARNES, A.; COOPER, W.; RODHES Measuring the efficiency of decision marking units, European Operational Research, vol. 2, n 6, pp. 429-444, 1978.

CHARNES, A.; COOPER, W.; LEWIN, A.; SEIFORD, L. Data envelopment analysis: theory, methodology and application. Boston: Kluwer Academic Publishers, 1994.

COOPER, W.; SEIFORD, L.; TONE, K. Data envelopment analysis: a comprehensive text with models, applications, references and DEA-Solver software. Boston: Kluwer Academic Publishers, 2000.

COOPER, W.; SEIFORD, L.; TONE, K. Introduction to data envelopment analysis and its uses. New York: Springer, 2006. 
EPSTEIN, M.; HENDERSON, J. Data envelopment analysis for managerial control and diagnosis, Decision Sciences, vol. 20, n 1, pp. 90-119, 1989.

FANDEL, G. On the performance of universities in North Rhine-Westphalia, Germany government's redistribution of funds judged using DEA efficiency measures, European Journal of Operational Research, vol. 176, n 1, pp. 521-533, 2007.

FARRELL, M. The measurement of productive efficiency, Journal of the Royal Statistical Society, series A, vol. 120, n³ 3, pp. 253-281, 1957.

FARRELL, M.; FIELDHOUSE, M. Estimating efficient production frontiers under increasing returns to scale. Journal of the Royal Statistical Society, series A, vol. 125, n 3, pp. 252-267, 1962.

GALBRAITH, K. Towards quality private higher education in Central and Eastern Europe, Higher Education in Europe, vol. 28, n 4, pp. 539-559, 2003.

GARVER, M. Best practices in identifying customer-driven improvement opportunities, Industrial Marketing Management, vol. 32, n 1, pp. 455-466, 2003.

GRÖNROOS, C. Service reflections: service marketing comes of age. In: Swartz, T. e Iacobucci, D. (Eds.), Handbook of service marketing and management. London: Sage Publications, pp. 13-16, 2000.

GRÖNROOS, C.; OJASALO, K. Service productivity: towards a conceptualization of the transformation of inputs into economic results in services, Journal of Business Research, vol. $57, \mathrm{n}^{\circ} 1, \mathrm{pp} .414-423,2004$.

HAIR Jr., J.; BABIN, B.; MONEY, A.; SAMOUEL, P. Essentials of business research methods. New Jersey: John Wiley \& Sons, 2003.

JOHNES, J. Data envelopment analysis and its application to the measurement of efficiency in higher education", Economics of Education Review, vol. 25, n 1, pp. 273-288, 2006.

JONGBLOED, B.; ENDERS, J.; SALERNO, C. Higher education and its communities: interconnections, interdependencies and research agenda", Higher Education, vol. 56, pp. 303-324, 2008.

KANTABUTRA, S.; TANG, J. Efficiency analysis of public universities in Thailand, Tertiary Education and Management, vol. 16, n 1, pp. 15-33, 2010.

KIRKLEY, J.; FÄRE, R.; GROSSKOPF, S.; MCCONNELL, K.; STRAND, I.; SQUIRES, D. Assessing capacity in fisheries when data are limited, North American Journal of Fisheries Management, vol. 21, n 3, pp. 482-497, 2001.

KOTLER, P. Marketing management: analysis, planning, implementation and control. Englewood Cliffs, New Jersey: Prentice Hall, 2003. 
MAINARDES, E.; ALVES, H.; DOMINGUES, M. Which factors are important to attract students for undergraduate administration courses?, The FedUni Journal of Higher Education, vol. 4, $\mathrm{n}^{\circ} 1, \mathrm{pp} .84-102,2009$.

SARRICO, C.; DYSON, R. Using DEA for planning in UK universities: an institutional perspective, Journal of the Operational Research Society, vol. 51, n 7, pp. 789-800, 2000.

SCHEERENS, J. Improving school effectiveness. Paris: UNESCO, 2000.

SHAW, E. A general theory of systems performance criteria, International Journal of General Systems, vol. 38, n 8, pp. 851-869, 2009.

VARGO, S.; LUSCH, R. Evolving to a new dominant logic for marketing, Journal of Marketing, vol. 68, $\mathrm{n}^{\circ}$ 1, pp.1-17, 2004.

WEICK, K. Educational organizations as loosely coupled systems. Administrative Science Quarterly, vol. 21, pp. 1-19, 1976.

YOUN, J.; PARK, K. University development models and efficiency analysis, Journal of Service Science, vol. 1, n 1, pp. 9-30, 2009.

ZHU, J. Quantitative models for performance evaluation and benchmarking: data envelopment analysis with spreadsheets. 2 ed. New York: Springer, 2009. 